\title{
ANAEROBIC CO-DIGESTION OF MICROALGAE WITH FOOD WASTE AND WASTEWATER SLUDGE
}

\author{
A Thesis \\ presented to \\ the Faculty of California Polytechnic State University,
}

San Luis Obispo

In Partial Fulfillment

of the Requirements for the Degree

Master of Science in Civil and Environmental Engineering

by

Ruth E. Spierling

June 2011 
(C) 2011

Ruth E. Spierling

ALL RIGHTS RESERVED 
COMMITTEE MEMBERSHIP

TITLE:

ANAEROBIC CO-DIGESTION OF MICROALGAE

WITH FOOD WASTE AND WASTEWATER SLUDGE

AUTHOR:

Ruth E. Spierling

DATE SUBMITTED:

June 2011

COMMITTEE CHAIR: Dr. Tryg Lundquist

COMMITTEE MEMBER: Dr. Yarrow Nelson

COMMITTEE MEMBER: Dr. Raul Cano 


\begin{abstract}
ANAEROBIC CO-DIGESTION OF MICROALGAE WITH FOOD WASTE AND WASTEWATER SLUDGE
\end{abstract}

Ruth E. Spierling

This research sought to optimize anaerobic co-digestion of microalgae biomass harvested from a wastewater treatment pond facility with locally-available wastes. The goal was to produce high methane yields and stable digestion without the need for supplemental alkalinity addition. A key research question was if algae digestion could be improved via the synergistic effects of co-digestion. Cell disruption to increase digestibility was not pursued due to its relatively high mechanical complexity and high energy use. For the wastewater treatment ponds studied, the most practical co-substrates identified were municipal wastewater sludge and food waste (sorted organic municipal waste). Although wastewater sludge does not have a particularly high carbon:nitrogen $(\mathrm{C}: \mathrm{N})$ ratio, it readily and stably digests and is available in large quantities at wastewater treatment plants. This research investigated the methane productivity of algae co-digestion with municipal wastewater sludge and food waste in semi-continuous bench-scale anaerobic digesters at $37.5^{\circ} \mathrm{C}$. Digesters fed pure algae biomass loaded at a rate of $4 \mathrm{~g}$ Volatile Solids (VS)/L-day with a 20-day residence time exhibited stable digestion and yielded an average of $0.23 \mathrm{~L} \mathrm{CH}_{4} / \mathrm{g} \mathrm{VS}_{\text {Introduced. }}$ For digesters that contained algae biomass in the feed, the greatest methane yield of $0.40 \mathrm{~mL} \mathrm{CH}_{4} / \mathrm{g} \mathrm{VS}_{\text {in }}$ was observed in a digester containing $50 \%$ algae co-digested with both sorted organic municipal waste $(40 \%)$, and municipal wastewater sludge (10\%) at a loading rate of $2 \mathrm{~g}$ VS/L-day with a 20-day 
residence time. While adding co-substrates increased yields in all digesters, prevention of ammonia toxicity did not appear to be the mechanism. Instead, the co-substrates simply increased the concentration of readily-digestible organic carbon, leading to increased methane yields and productivities. For algae biomass, total ammonia nitrogen concentrations of $3370 \mathrm{mg} / \mathrm{L}$ did not appear to inhibit methane yield. Digesters with the same feed contents and residence time loaded at 2 and $4 \mathrm{~g} \mathrm{VS} / \mathrm{L}-\mathrm{d}$ had similar yields but total ammonia nitrogen concentrations of 1740 and $3370 \mathrm{mg} / \mathrm{L}$ respectively. From the data from these laboratory studies, descriptive models were developed for ammonia nitrogen, alkalinity, volatile fatty acids, yield, biogas quality, and volatile solids destruction. The variables from the descriptive models with p-values above 0.05 were then used to create a compact model.

Keywords: Anaerobic Digestion, Microalgae, Biofuels, Co-digestion, Methane. 


\section{ACKNOWLEDGMENTS}

I would like to thank:

Dr. Tryg Lundquist for giving me the best guidance possible, challenging me, listening to me, and especially for sometimes letting me be a mad scientist;

Dr. Yarrow Nelson, Dr. Raul Cano and Dr. David Brune for your input while creating this project and thesis;

Craig Stubler for letting sludge and algae go where sludge and algae have never gone before;

Dan Heimel for being my understanding research partner;

Sean Thompson for getting it done no matter what it was;

Research partners and other students for your support, understanding, and sense of humor;

The California Energy Commission, Energy Innovation Small Grants Program, and the Carbon Capture Corporation for their financial support;

The Sunnyvale Water Pollution Control Plant and the San Luis Obispo Water Reclamation Facility for their assistance and generous donation of algae float and municipal sewage sludge. 


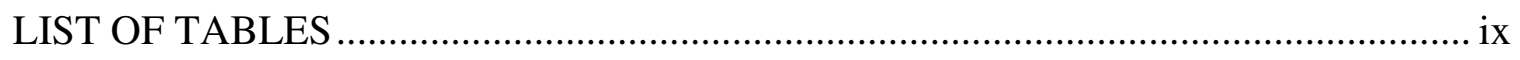

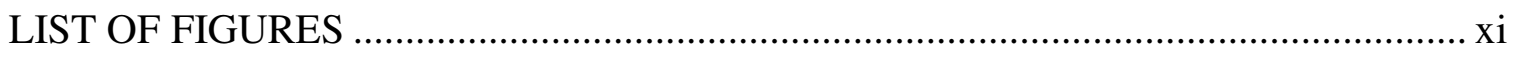

INTRODUCTION .... -

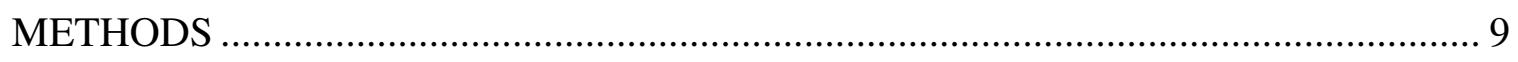

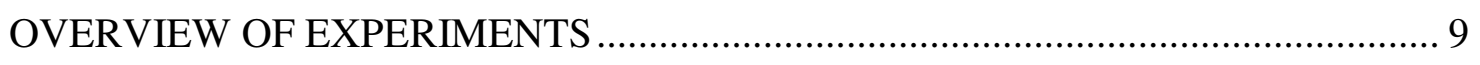

COLLECTION AND STORAGE OF ALGAE ........................................................ 10

COLLECTION AND STORAGE OF SLUDGE AND ADAPTED INOCULUM ...... 10

COLLECTION AND STORAGE OF FOOD WASTE ............................................... 11

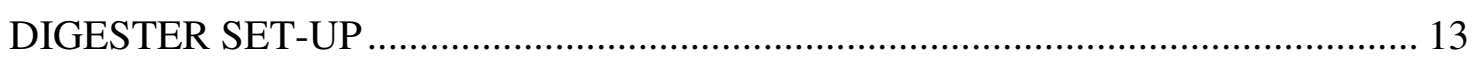

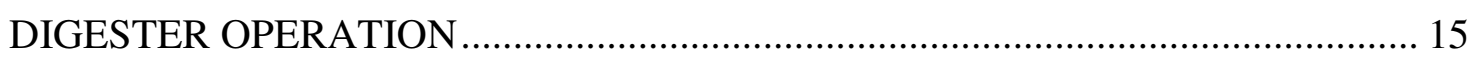

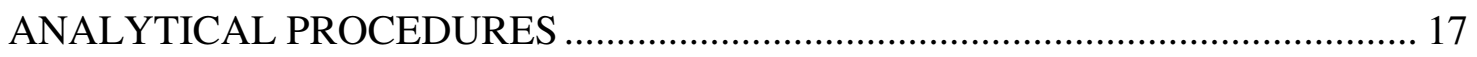

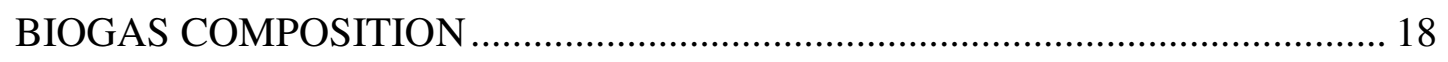

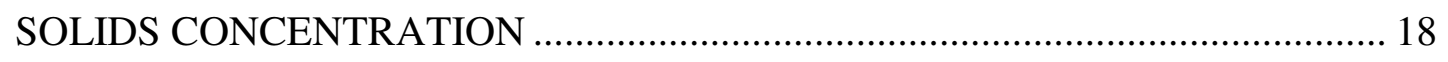

VOLATILE FATTY ACIDS, pH, ALKALINITY, AND AMMONIA NITROGEN

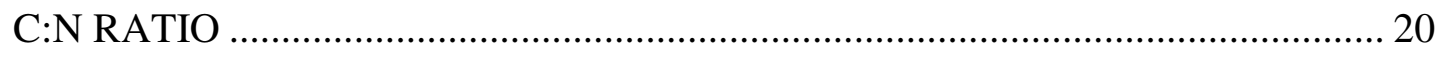

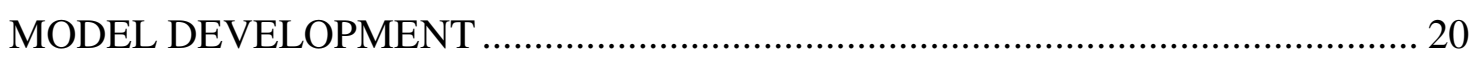


INFLUENCE OF FEED COMPOSITION, ORGANIC LOADING RATE AND

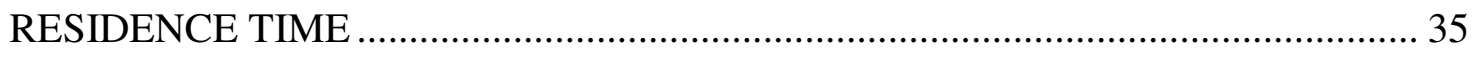

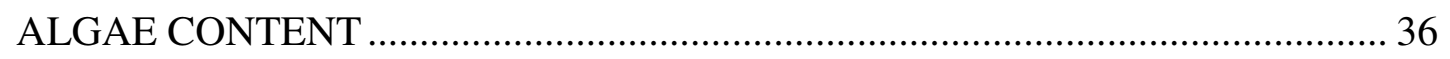

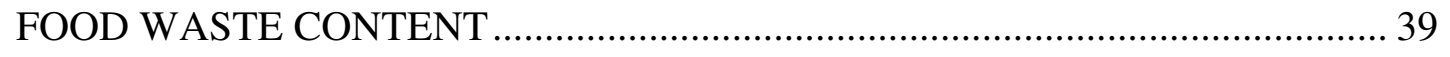

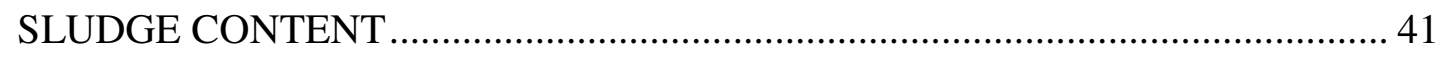

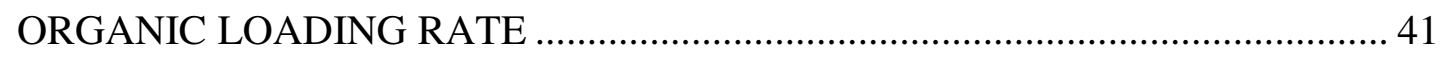

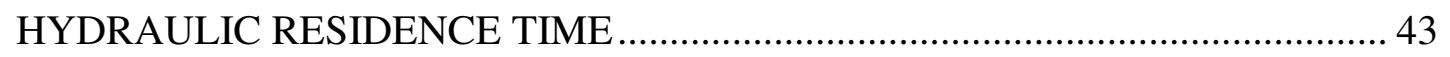

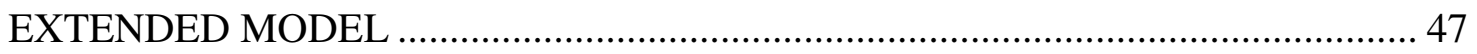

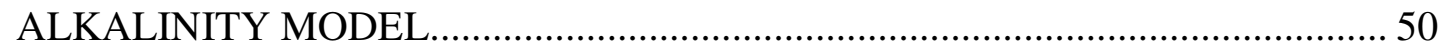

VOLATILE FATTY ACIDS MODEL ………………………………………..... 53

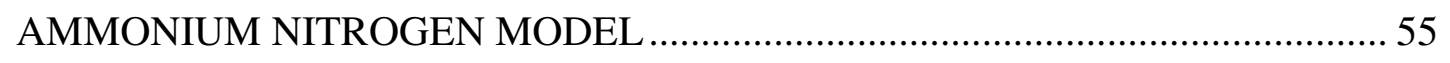

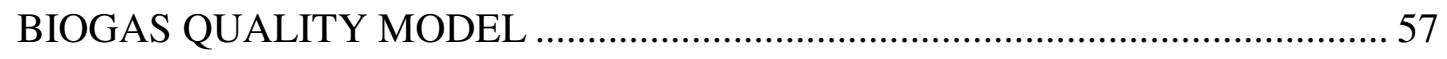

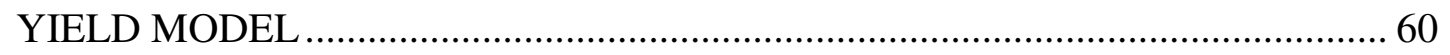

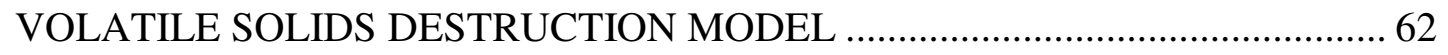

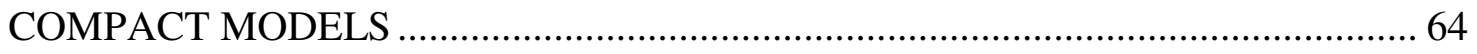

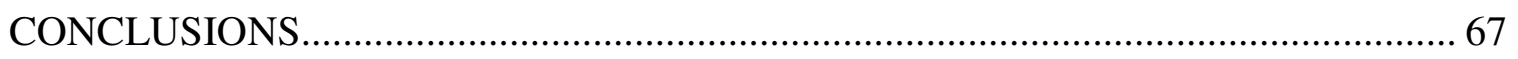

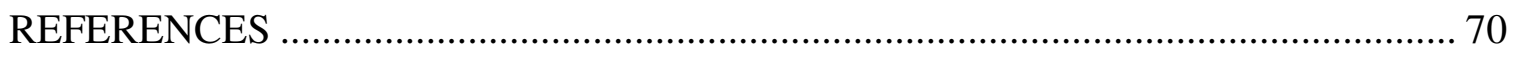




\section{LIST OF TABLES}

Table

Table 1: Experiment 1 Conditions

Table 2: Experiment 2 Conditions 17

Table 3: Average steady state values calculated by determining the intersection of steady state periods for gas production, volatile solids destruction (VSD), $\mathrm{pH}$, and alkalinity, ammonium, and volatile fatty acids concentrations. The line down the middle of the graph separates independent variables on the left from dependent variables on the right.

Table 4: Model steady state periods and the number of values averaged for each value used in the model.

Table 5: Statistical analysis of the influence of residence time, organic loading rate, and algae and food waste content in the feed on alkalinity concentrations in the digester effluents.

Table 6: Statistical analysis of the influence of residence time, organic loading rate, and algae and food waste content in the feed on volatile fatty acid concentrations in the digester effluents.

Table 7: Statistical analysis of the influence of residence time, organic loading rate, and algae and food waste content in the feed on ammonia nitrogen concentrations in the digester effluents. 
Table 8: Statistical analysis of the influence of residence time, organic loading rate, and algae and food waste content in the feed on the methane content in the biogas........ 58

Table 9: Statistical analysis of the influence of residence time, organic loading rate, and algae and food waste content in the feed on the methane yield....

Table 10: Statistical analysis of the influence of residence time, organic loading rate, and algae and food waste content in the feed on volatile solids destruction.

Table 11: Compact model statistics showing the influence of organic loading rate and food waste content in the feed on digester volatile fatty acid concentration.

Table 12: Compact model statistics showing the influence of algae and food waste content in the feed on volatile solids destruction. 


\section{LIST OF FIGURES}

Figure

Figure 1: The primary species present in the algae biomass was chodatella, shown in the picture on the far right. Other algae species present in the algae biomass included chlorella, anacystis, euglena, ulothrix, ankistrodesmus, pediastrum, zygnema, scenedesmus, oocystis, schizothrix, closterium, cyclotella, fragilaria, micractinium,

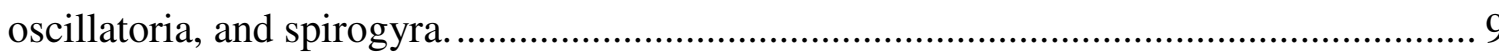

Figure 2: Food waste composition (January 2010) by wet mass................................. 12

Figure 3: Digester set-up inside an incubator. Digesters 2.1-2.5 are on the top shelf while their inverted gas collectors are on the bottom of the incubator.

Figure 4: Digester effluent characteristics over time for Digester 2.2 (100\% algae feed at $4 \mathrm{~g} \mathrm{VS/L-d} \mathrm{and} \mathrm{a} \mathrm{20-day} \mathrm{residence} \mathrm{time)} \mathrm{are} \mathrm{shown} \mathrm{as} \mathrm{an} \mathrm{example} \mathrm{of} \mathrm{the} \mathrm{data}$ collected for all digesters in the study. Using the criteria described in this text, the model steady state period for this digester was determined to be Days 62-83. The decreases in $\mathrm{pH}$, and alkalinity during Days 45 through 60 were caused by inadvertent declining of the digester volume

Figure 5: Digester 2.2 (100\% algae feed at $4 \mathrm{~g}$ VS/L-d and a 20-day residence time) biogas production and methane yield over time. The dip in biogas production from Day 40-55 was probably caused by the gradually decreasing digester volume described in the text. This dip at Day 55 led to exclusion of these data using the steady state selection criteria. Additionally, many other yield data points beyond 
the model steady state period met the criteria but were excluded because solids concentrations or digester effluent characteristics were not at steady state at that time... 26

Figure 6: Digester 2.2 (100\% algae feed at $4 \mathrm{~g}$ VS/L-d and a 20-day residence time) solids data. Total solids concentration in the effluent appeared to stabilize around Day 48

Figure 7: Digester effluent characteristics over time for Digester 1.5 (100\% sludge feed at $2 \mathrm{~g} \mathrm{VS} / \mathrm{L}-\mathrm{d}$ and a 20-day residence time) are shown as an example of the most digester over time. In this case, the model steady state period was determined to be Day 29-50. 28

Figure 8: Digester 1.5 (100\% sludge feed at $2 \mathrm{~g} \mathrm{VS/L-d} \mathrm{and} \mathrm{a} \mathrm{20-day} \mathrm{residence} \mathrm{time)}$ biogas production and methane yield over time. This digester showed the least variation for all measurements over time.

Figure 9: Digester 1.5 (100\% sludge feed at $2 \mathrm{~g} \mathrm{VS/L-d} \mathrm{and} \mathrm{a} \mathrm{20-day} \mathrm{residence} \mathrm{time)}$ solids data. Total solids concentration in the digester effluent decreased slightly for the duration of the experiment while volatile solids destruction increased slightly. This is in direct contrast to the algae digesters; however, the slope of decreasing total solids is significantly less than the slope of increasing total solids in the algae digesters..... 30

Figure 10: Digester effluent characteristics over time for Digester 2.8 (40\% algae, $50 \%$ food waste, and $10 \%$ sludge feed at $5.5 \mathrm{~g} \mathrm{VS} / \mathrm{L}-\mathrm{d}$ and a 20 -day residence time). In this case, the model steady state period was determined to be Day 41-55. Although this steady state period shows a steadily decreasing $\mathrm{pH}$ and high volatile fatty acids values the alkalinity values remain fairly stable and the values meet the 
steady state criteria. Although earlier periods show more stable $\mathrm{pH}$ and volatile fatty acids, the period after the first residence time was particularly unstable in terms of biogas production and yield (Figure 10)

Figure 11: Digester 2.8 (40\% algae, 50\% food waste, and 10\% sludge feed at 5.5 g VS/L-d and a 20-day residence time) biogas production and methane yield over time. The model steady state period of Day 41-55 avoids any extreme dips or peaks in biogas production and yield. By Day 60, Digester 2.8 experienced complete digester collapse, and despite the reintroduction of methanogens and a $\mathrm{pH}$ adjustment, the digester was unable to maintain a steady $\mathrm{pH}$ and biogas production for the remainder of the experiment. Continuous or semi continuous alkalinity addition would probably be needed to maintain healthy digestion with these feeds at this high loading rate.

Figure 12: Digester 2.8 (40\% algae, 50\% food waste, and $10 \%$ sludge feed at 5.5 g VS/L-d and a 20-day residence time) solids data. The solids data reflects the digester instability with digester solids increasing and peaking right before culture crash.

Figure 13: Effect of algae content in the feed on methane yield, percent of volatile solids destroyed and methane content in the biogas for digesters fed only algae and sludge at a rate of $2 \mathrm{~g} \mathrm{VS/L-day} \mathrm{and} \mathrm{a} \mathrm{20-day} \mathrm{residence} \mathrm{time.} \mathrm{Duplicate} \mathrm{digesters} \mathrm{are}$ not averaged.

Figure 14: The effect of algae content in the feed on methane yield, percent of volatile solids destroyed and biogas quality when various residence times and loading 
rates are included in the data set. Values for digesters with the same algae content in the feed were averaged. Averaging the values diminishes the effect of some influential variables such as food waste and allows the effect of algae feed to be seen independently of the other variables.

Figure 15: Effect of food waste in the feed on yield, percent methane, and volatile solids destruction. This graph shows the average value for the three different percentages of food waste in the feed.

Figure 16: The effect of organic loading on methane yield, volatile solids destruction, and percent methane in the biogas for pairs of digesters with the same residence time and feed composition

Figure 17: Comparison of three digesters fed $80 \%$ algae and $20 \%$ sludge. Digester 1.10 and 2.3 were fed at a rate of $2 \mathrm{~g} \mathrm{VS/L-day} \mathrm{and} \mathrm{a} \mathrm{20-day} \mathrm{residence} \mathrm{time,} \mathrm{and}$ Digester 2.10 was fed at a rate of $1 \mathrm{~g} \mathrm{VS} / \mathrm{L}$-d and a 40-day residence time. 45

Figure 18: Plot showing the predicted alkalinity concentration as determined from the extended model equation compared to the actual measured average alkalinity concentration for the steady state period. The dashed line indicates the one to one line while the solid line indicates the line of best fit for the data points

Figure 19: Plot showing the predicted volatile fatty acid concentration as determined from the extended model equation compared to the actual measured average volatile fatty acid concentration for the steady state period. The dashed line indicates the one to one line while the solid line indicates the line of best fit for the data points. 
Figure 20: Plot showing the predicted ammonia nitrogen concentration as determined from the extended model equation compared to the actual measured average ammonia nitrogen concentration for the steady state period. The dashed line indicates the one to one line while the solid line indicates the line of best fit for the data points.

Figure 21: Plot showing the predicted biogas quality as determined from the extended model equation compared to the actual measured average biogas quality for the steady state period. The dashed line indicates the one to one line while the solid line indicates the line of best fit for the data points.

Figure 22: Plot showing the predicted yield as determined from the extended model equation compared to the actual measured average yield for the steady state period. The dashed line indicates the one to one line while the solid line indicates the line of best fit for the data points

Figure 23: Plot showing the predicted volatile solids destruction as determined from the extended model equation compared to the actual measured average volatile solids destruction for the steady state period. The dashed line indicates the one to one line while the solid line indicates the line of best fit for the data points 


\section{INTRODUCTION}

As of 2009, 11.6\% of the energy produced in California came from renewable resources, with energy from biomass comprising about one fifth of all renewable energy produced (CEC 2011), and the State government has set progressive renewable energy goals over the past several years. In April 2011, California State Bill X12 was signed into law mandating that one-third of California's energy come from renewable sources by 2020 (CEC 2011). Additionally, California's Bioenergy Action Plan (2006) lists as its primary goal to make California a leader in biomass use and technologies by mandating the cooperation of regulatory agencies to encourage the use of native biomass and facilitating research, demonstration, and commercialization of biomass technologies, so California can achieve its goals for renewable energy, reducing greenhouse gasses, and energy independence.

As one of the oldest and simplest methods of processing organic solids into biofuels, anaerobic digestion is a potentially important source of renewable fuel. For example, the California Energy Commission (CEC) has been aggressively funding research for underdeveloped sources of biomass for anaerobic digestion such as dairy wastes, food wastes, other agricultural wastes, and recently, algae biomass. The current main barrier to further implementation of anaerobic digestion in California is not feedstock supply but rather low return on investment for new digesters. Digester investment is hard to justify on fuel economics alone due to high capital costs and the low cost of the competing fuel, natural gas (Germain and Katofsky, 2006). To meet the State renewable energy goals, favorable economic or regulatory incentives will be needed, and low-cost waste 
feedstocks need to be identified (Germain and Katofsky, 2006). Additionally, the need for waste biomass disposal can be another economic driver to encourage the use of anaerobic digestion, such as for wastewater treatment sludge.

Microalgae are a leading biofuel feedstock candidate, with liquid transportation fuel such as biodiesel being the highest value target, but many years of research and development are likely needed before liquid algae fuel production is commercialized (DOE Algal Biofuels Roadmap 2010). Due to the relatively uncomplicated technology used with anaerobic digestion, it is a more straightforward and near-term way to produce biofuels from algae. Additionally, the commonly proposed model of liquid microalgae biofuel production requires that algal biomass residuals after oil extraction are digested to recover additional fuel, carbon, and nutrients (Lundquist et al. 2010).

Wastewater treatment ponds are a ready source of algae biomass for biogas production. With over four hundred waste treatment pond systems in California, the amount of microalgae biomass grown in these treatment systems is estimated to be near 26,000 dry metric tons per year (Lundquist 2007). At some treatment plants, suspended solids are removed from the pond effluent to meet discharge or reuse requirements. The algae are typically coagulated with alum and/or organic polymers and separated by dissolved air flotation (e.g., the California cities of Sunnyvale, Stockton, and Modesto) or sedimentation (e.g., Napa Sanitation District). Algae disposal for most of these treatment systems consists of returning the harvested algae back to the treatment pond where it degrades anaerobically, potentially emitting methane and other air pollutants, as well as releasing from the cells nutrients and oxygen-demanding substances back into the 
wastewater. In the past, some of the operators of these treatment systems have attempted to remedy this situation by anaerobically digesting the harvested algae with primary sludge, with the intention to dispose of the combined digested sludge by dewatering and export from the site. However, changes in the digester effluent color and odor led operators to discontinue this practice after a short time in order to avoid potential digester upset (Da Sa J., pers. comm. 2009, EAO, Inc. \& Bracewell Engineering, Inc. 1988).

Algae digestion research has been conducted since the 1950s, with a recent resurgence of research in conjunction with algae transportation fuels research. Past research identified two major obstacles to high methane yields when digesting freshwater algae: cell walls that resist breakdown and a high protein content that can result in ammonia toxicity (Sialve et al. 2009). The most common solutions to overcome these obstacles include algae cell pre-treatment which seeks to weaken or disrupt algae cell walls, co-digestion which tries to balance the relatively high nitrogen concentration in algae with another high carbon substrate to prevent ammonia toxicity, and altering digestion conditions such as residence time, reactor shape, loading rates, and digestion temperature (Sialve et al. 2009). In some cases, co-digestion has led to a synergistic effect where the amount of methane produced exceeded the amount expected by the individual digestion of each cosubstrate (Samson and LeDuy 1983, Yen and Brune 2007).

The concept of using microalgae biomass to produce biogas originated with Golueke, Oswald, and Gotaas (1957). They hypothesized that algae cell walls resist bacterial degradation, which allows algae to survive at normal digestion times and temperatures. Therefore, they sought to damage cell walls by increasing the digestion temperature from 
$35^{\circ} \mathrm{C}$ to $50^{\circ} \mathrm{C}$, which increased methane yields $19 \%$ from an average of $0.25 \mathrm{~L} \mathrm{CH}_{4} / \mathrm{g}$ volatile solids (VS) introduced to an average of $0.31 \mathrm{~L} \mathrm{CH}_{4} / \mathrm{g}$ VS introduced . Chen and Oswald (1998) found lower biogas yield from algae biomass compared to raw municipal wastewater sludge unless the algae biomass was pre-treated by heating algae cells at $100^{\circ} \mathrm{C}$ for eight hours before digestion. Although this was found to increase methane yield by up to $33 \%$, pretreating was also found to be energy intensive with the energy input for heat treating exceeding the energy gained through improved digestion. To date, insufficient research on algae cell pretreatment has been performed to show that the extra energy output can justify the energy input.

Microalgae biomass generally has a lower carbon-to-nitrogen $(\mathrm{C}: \mathrm{N})$ ratio than optimal for anaerobic digestion, and one focus of algae digestion research has been increasing the C:N ratio in the feed to improve digestion (Yen and Brune 2007, Chen 1987, Samson and LeDuy 1983). This technique relies on the hypothesis that the low C:N ratio present in typical algae biomass produces compounds inhibitory to the digestion process, mainly ammonia, when digested. By co-digesting algae with low-cost, high-carbon wastes, the ammonia nitrogen concentration can be diluted, potentially decreasing ammonia inhibition. Yen and Brune (2005) co-digested waste paper with algae and found an optimum C:N ratio for methane production of 20:1-25:1, similar to the optimum for other substrates. Adding paper to the digester also increased the methane yield $50 \%$ above algae digestion alone. They also speculated that paper addition increased cellulase activity, helping to breakdown algae cell walls. 
Food waste, in the form of sorted organic municipal waste, remains an under-exploited source of waste carbon in the United States. Studies have shown it to be carbon-rich and highly digestible. For example, a 2007 study of sorted organic municipal waste found that it was possible to use food waste as the sole substrate in a stable digestion process. The methane yields from this 28-day batch study were 0.348 to $0.435 \mathrm{~L} \mathrm{CH}_{4} / \mathrm{g}$ VS introduced (Zhang et al. 2007).

As mentioned above, municipal wastewater sludge is another potential co-substrate for algae digestion, but this sludge typically contains significantly less carbon than food waste. However, sludge is abundant and already collected at wastewater treatment plants. Samson and LeDuy (1983) found that by changing digester feeds from 100\% algae to equal parts municipal wastewater sludge and algae, methane yield more than doubled compared to a pure algae digester. They also found a synergistic effect when they added peat hydrolyzate and municipal wastewater sludge to algae digesters.

An unexplored option for overcoming ammonia toxicity and inhibition in the algae digestion field is the use of ammonia adapted cultures. McCarty (1964) states that at higher $\mathrm{pH}$ values, ammonia concentrations from 1,500 to $3,000 \mathrm{mg} \mathrm{N} / \mathrm{L}$ are inhibitory to methane production, and concentrations over $3,000 \mathrm{mg} \mathrm{N} / \mathrm{L}$ create toxic conditions where methane production ceases. However, since 1971 extensive research has been performed on the ability of anaerobic cultures to adapt to high ammonia concentrations, and Koster and Lettinga (1988) found that for potato juice anaerobic digestion could proceed until ammonia concentrations reached $11,800 \mathrm{mg} \mathrm{N} / \mathrm{L}$. Furthermore, Hashimoto (1986) found that by digesting cattle wastes with adapted cultures, ammonia inhibition 
did not occur until concentrations exceeded 4,000 $\mathrm{mg} \mathrm{N} / \mathrm{L}$. This presents the possibility that ammonia toxicity or inhibition in algae digesters could be avoided by using ammonia adapted cultures. This would be ideal in places where the import of carbon-rich cosubstrates is not possible or affordable.

The primary objective of this study was to provide information regarding the loading rates, residence times, and amount of algae in the feed that would lead to stable digestion to wastewater treatment plants with algae biomass. Other experimental objectives included validating past methane yield numbers for waste-grown algae using loading rates, retentions times, and digester feed configurations that would most likely be used at existing wastewater treatment plants, and determining the yield and stability of mixtures of algae, municipal wastewater sludge, and food waste. Food waste and sludge were chosen as the co-substrates because, unlike many sources of organic carbon, they are relatively inexpensive and readily and consistently available in large quantities.

Synergistic effects, like those seen in Yen and Brune (2007) and Sampson and LeDuy (1983), between substrates were expected due to lower ammonia nitrogen concentrations relative to the carbon concentrations, and improved digester stability with lower volatile fatty acid concentrations, higher $\mathrm{pH}$ and alkalinity concentrations, and a higher methane yield per gram of introduced volatile solids. In order to identify any synergistic effect of co-digestion, a range of co-digestion substrate ratios were tested. Several organic loading rates and sludge residence times were used in an attempt to find the optimal digestion conditions in terms of digester stability and methane yield. The digesters were also 
inoculated with ammonia adapted cultures from a wastewater treatment plant in order to determine the effect of adapted cultures on ammonia inhibition and methane yield.

The purpose of this work was to determine the optimal mixture of algae, municipal wastewater sludge, and food waste to improve the methane yield and process stability of algae digestion. Additionally, four organic loading rates and two hydraulic residence times were tested. The organic loading rates used in this experiment were low ranging from 1-5.5 g VS/L-d. While stable digestion could possibly be maintained at higher organic loading rates, it would most likely require frequent addition of alkalinity to maintain $\mathrm{pH}$ levels in the optimum region and prevent digester upset. Adding frequent doses of alkalinity may be unpractical and uneconomical in most algae digestion situations, therefore, the organic loading rates and residence times investigated in this study were only those that resulted in stable digestion.

From the data these experiments produced, two models were developed: an extended model that describes the results of the experiment and a compact model using the variables with the strongest p-values from the extended model. The compact model might be used by wastewater treatment facilities that produce algae biomass to determine the optimum digestion conditions for methane yield and digester stability. Information on the potential to scale-up algae digestion at the facility level is described in a companion thesis (Heimel 2010).

There are still many unanswered questions and technology gaps in the field of algae digestion such as an economical and energy efficient ways to access carbon trapped 
within and behind the algae cell walls. In addition, the demand for algae digestion technologies is increasing and is important to potential future algae liquid biofuel production, which is likely to depend on the effectiveness of digesting cell debris after cell disruption for lipid extraction and the recycling of nutrients back to algae ponds through the digestion process (Golueke et al. 1957, Lundquist et al. 2010). 


\section{METHODS}

\section{OVERVIEW OF EXPERIMENTS}

Two primary experiments were performed in 1-L laboratory digester flasks. In the first experiment, eight digesters were fed mixtures of algae and municipal wastewater sludge. In the second experiment, ten digesters were fed mixtures of algae, sludge, and food waste and several organic loading rates and residence times were tested. The first experiment was called Experiment 1 and the Digesters 1.1-1.2, and 1.5-1.10 and the second experiment was called Experiment 2 and the Digesters 2.1-2.10.

To provide consistent feed characteristics, the sludge and food waste were each collected in a single batch, homogenized, and frozen. Biomass from wastewater treatment ponds contains a mix of algae, bacteria, and organic detritus, but this mixture will be referred to as algal biomass or algae in this paper. Microscopic examination indicated that the biomass was predominantly algae cells (Figure 1).
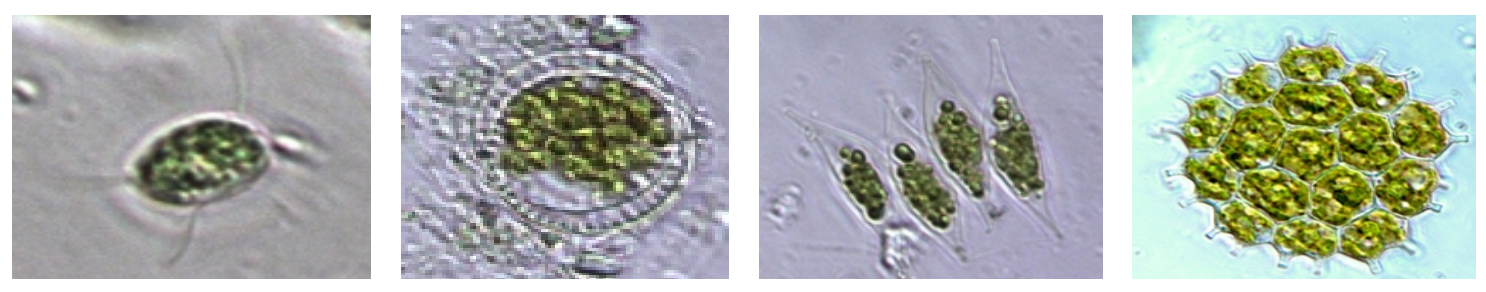

Figure 1: The primary species present in the algae biomass was chodatella, shown in the picture on the far right. Other algae species present in the algae biomass included chlorella, anacystis, euglena, ulothrix, ankistrodesmus, pediastrum, zygnema, scenedesmus, oocystis, schizothrix, closterium, cyclotella, fragilaria, micractinium, oscillatoria, and spirogyra. 


\section{COLLECTION AND STORAGE OF ALGAE}

The source of the algae biomass was the 29.5 MGD capacity City of Sunnyvale Water Pollution Control Plant at the southern end of San Francisco Bay, California. The Sunnyvale treatment process begins with primary settling followed by 440 acres of oxidation ponds, which provide secondary wastewater treatment and a habitat for growth of microalgae. From the oxidation ponds, the water travels to nitrifying biotowers with plastic media and then to dissolved air flotation tanks. At the dissolved air flotation tanks coagulating cationic polymer (Clarifloc WE-717 Polydyne Inc., RiceBoro Georgia) is dosed into the wastewater at concentrations of 4-8 ppm with an average dose of $4.2 \mathrm{ppm}$, and the algae biomass "float" is skimmed off the water surface in the tank (Da Sa J., pers. comm. 2009). The float collected for the experiments was then gravity separated in 20-L plastic pails for 12 hours during overnight transport. In the morning, the thickened float was homogenized in a single batch in a plastic wheelbarrow using concrete mixing hoes. The float was then distributed into 0.5 - $\mathrm{L}$ plastic bags and frozen at $-17^{\circ} \mathrm{C}$. The algae was collected on July 14, 2009, and had a moisture content of $86 \%$ at the time of freezing.

\section{COLLECTION AND STORAGE OF SLUDGE AND ADAPTED INOCULUM}

The City of San Luis Obispo Water Reclamation Facility, in central California, was the source of municipal wastewater sludge and digester inoculum. The facility uses primary setting tanks, followed by trickling filters, secondary settling, nitrifying activated sludge, tertiary settling, filtration, and disinfection. The sludge from primary, secondary, and tertiary setting tanks is thickened, in a dissolved air floatation thickener (DAFT). The primary sludge enters the DAFT at 2-3\% (weight/weight) solids content, while the 
secondary and tertiary sludges enter at $1 \%$ solids. Ferric chloride is added in the DAFT tank, and the mixed sludge exits the DAFT tank at 4-6\% solids. From the DAFT, the float sludge drains into the first of a series of three anaerobic digesters operated around $32.2{ }^{\circ} \mathrm{C}$ and with an average total hydraulic residence time of 60 days. The feed sludge used in the present experiments was collected from the float effluent pipe of DAFT, and the inoculum for the experimental digesters was collected from the effluent of the second digester.

The DAFT float sludge was frozen at $-17^{\circ} \mathrm{C}$ with a moisture content of $94 \%$ in $0.5-\mathrm{L}$ plastic bags. It contained a mixture of about $35 \%$ primary sludge mass, with the remainder being a mixture of secondary and tertiary sludges originating from the trickling filter and nitrifying activated sludge basins, respectively. The digesters of the first experiment were inoculated with municipal digester sludge (36\%) and digester contents from previous algae digestion experiments (64\%). Digesters of second experiment were inoculated with sludge from the digesters of the first experiment $(91 \%)$ and digester sludge $(9 \%)$. The inoculum was only used at the beginning of the experiment to provide adapted anaerobic and methanogenic cultures to the digesters, so it was not stored or frozen.

\section{COLLECTION AND STORAGE OF FOOD WASTE}

The food waste came from the food service operation of the California Polytechnic State University, San Luis Obispo. The food waste consisted of equal parts by mass of postconsumer wastes from a lunchroom, kitchen wastes, which consisted of unused and uneaten food from the cafeteria and food preparation wastes, which consisted primarily 
of fruit and vegetable skins. These wastes were mixed and blended with water in an industrial blender (700S, Waring, Torrington Connecticut), bagged and frozen at $-17^{\circ} \mathrm{C}$ with a moisture content of $80 \%$. No effort was made to exclude meat, bones, or paper from the food waste. Analysis of a sub-sample of the food waste revealed that, by mass, starches such as bread, rice, and noodles were the dominate food type followed by tomato. Overall, total fruit and vegetable waste accounted for nearly $50 \%$ of the food waste (Figure 2).

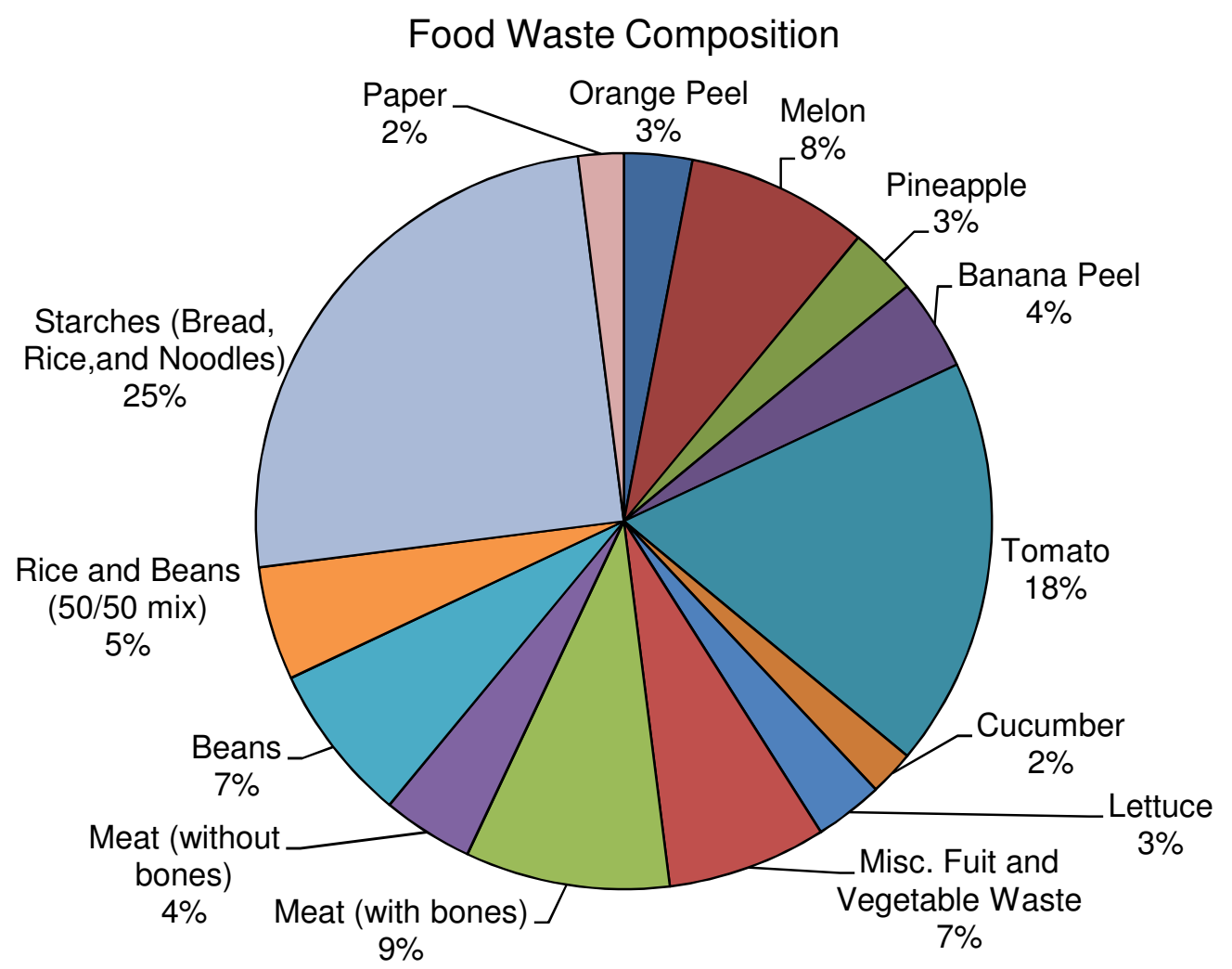

Figure 2: Food waste composition (January 2010) by wet mass. 


\section{DIGESTER SET-UP}

Each laboratory digester was a 2-L Erlenmeyer flask with a Size 13 butyl rubber stopper with two holes_-one for feeding and withdraw and one for biogas passage. Gas collection for each digester was measured by inverting a 2-L plastic graduated cylinder with graduation marks every $20-\mathrm{mL}$ with a $7.2-\mathrm{cm}$ inner diameter into a clear PVC, liquid-filled tube with a 10-cm inner diameter (Figure 3). The liquid in the tube was 5\% $\mathrm{H}_{2} \mathrm{SO}_{4}$ saturated with $\mathrm{NaCl}$ to prevent dissolution of biogas constituents. This cylinder was also outfitted with a sampling port with rubber septa allowing the biogas to be sampled with a gas-tight syringe. Digester feeding was accomplished using a 60-mL plastic syringe connected by tubing through the rubber stopper. Mixing was performed by hand before and after feeding by shaking each digester for $30 \mathrm{sec}$ by gripping the neck of the flask and moving it in a circular motion. A 25-mm long TFE-coated stir bar in each bottle ensured good agitation. Electric stirrers were not used. 


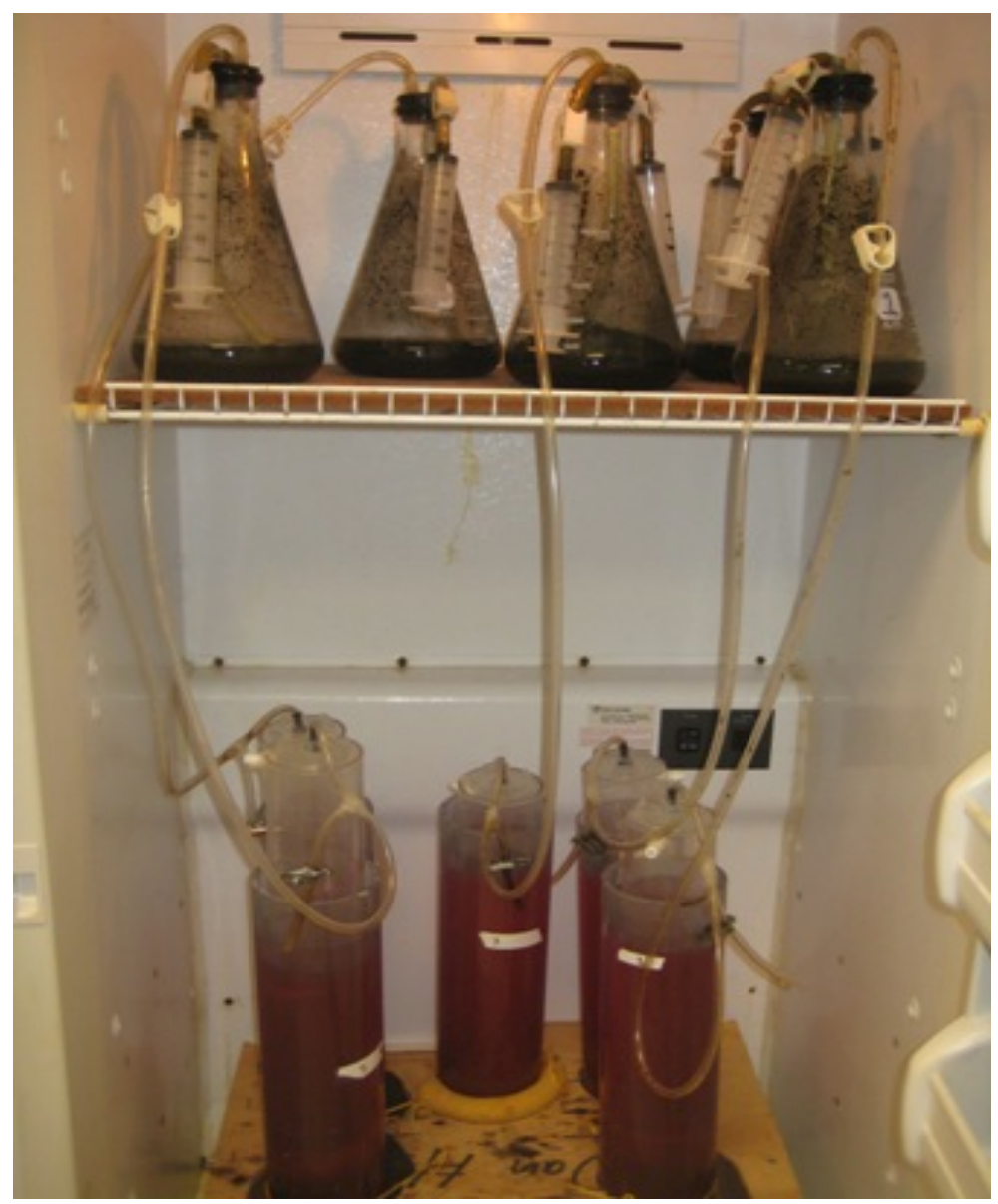

Figure 3: Digester set-up inside an incubator. Digesters 2.1-2.5 are on the top shelf while their inverted gas collectors are on the bottom of the incubator.

Before sampling each digester was agitated for 30 seconds to mix digester contents.

During sampling, before drawing the final sample, $60 \mathrm{~mL}$ of digester material was drawn into the syringe and then pushed back into the digester three times to clear the feeding tube of old material. After feeding, the syringe was filled and evacuated three more times to ensure that most of the fresh feed entered the main digester volume. After feeding, each digester was again agitated for 30 seconds to ensure good mixing of the feed with 
the digester contents. The digesters were placed in incubators set at $37.5^{\circ} \mathrm{C}$, the same temperature used at the full-scale Sunnyvale Water Pollution Control Plant digesters.

\section{DIGESTER OPERATION}

The different digestion variables that were explored in Experiments 1 and 2 included feed content (ratios of algae, sludge and food), organic loading rate, and residence time. In Experiment 1, the algae and sludge ratio in the feed was the only variable tested. The organic loading rate and residence time were set at $2 \mathrm{~g} \mathrm{VS} / \mathrm{L}-\mathrm{d}$ and 20 days for all eight digesters (Table 1). In Experiment 2, organic loading rate, residence time, and percent algae, sludge and food waste in the feed were the variables tested (Table 2). Digester 2.10 was set at a residence time of 40 days to test digestion stability and yield with a longer residence time. Four digesters were given feed containing $40 \%$ algae, $50 \%$ food waste, and $10 \%$ sludge at three different organic loading rates. An additional digester was given feed with $83.4 \%$ food waste and $16.6 \%$ sludge to provide digestion data without algae at a loading rate of $2 \mathrm{~g} \mathrm{VS/L-d.} \mathrm{Four} \mathrm{organic} \mathrm{loading} \mathrm{rates} \mathrm{of} \mathrm{1,} \mathrm{2,} \mathrm{4,} \mathrm{and} 5.5 \mathrm{~g}$ VS/L-day were used, and several algae, food waste, and sludge ratios in the feed were tested (Table 2). 
Table 1: Experiment 1 Conditions

\begin{tabular}{cccccc}
\hline \hline $\begin{array}{c}\text { Digester } \\
\text { Number }\end{array}$ & $\begin{array}{c}\text { HRT } \\
(\text { days })\end{array}$ & $\begin{array}{c}\text { OLR } \\
(\mathrm{g} \mathrm{VS} / \mathrm{L} \mathrm{d})\end{array}$ & $\begin{array}{c}\text { Algae } \\
\text { Fraction } \\
(\%)\end{array}$ & $\begin{array}{c}\text { Food } \\
\text { Waste } \\
\text { Fraction } \\
(\%)\end{array}$ & $\begin{array}{c}\text { Sludge } \\
\text { Fraction } \\
(\%)\end{array}$ \\
\hline 1.5 & 20 & 2 & 0 & 0 & 100 \\
1.6 & 20 & 2 & 20 & 0 & 80 \\
1.7 & 20 & 2 & 40 & 0 & 60 \\
1.8 & 20 & 2 & 60 & 0 & 40 \\
1.9 & 20 & 2 & 60 & 0 & 40 \\
1.10 & 20 & 2 & 80 & 0 & 20 \\
1.1 & 20 & 2 & 100 & 0 & 0 \\
1.2 & 20 & 2 & 100 & 0 & 0 \\
\hline
\end{tabular}


Table 2: Experiment 2 Conditions

\begin{tabular}{cccccc}
\hline $\begin{array}{c}\text { Digester } \\
\text { Number }\end{array}$ & $\begin{array}{c}\text { HRT } \\
(\text { days })\end{array}$ & $\begin{array}{c}\text { OLR } \\
(\mathrm{g} \text { VS/L d })\end{array}$ & $\begin{array}{c}\text { Algae } \\
\text { Fraction } \\
(\%)\end{array}$ & $\begin{array}{c}\text { Food } \\
\text { Waste } \\
\text { Fraction } \\
(\%)\end{array}$ & $\begin{array}{c}\text { Sludge } \\
\text { Fraction } \\
(\%)\end{array}$ \\
\hline 2.1 & 20 & 4 & 100 & 0 & 0 \\
2.2 & 20 & 4 & 100 & 0 & 0 \\
2.3 & 20 & 2 & 80 & 0 & 20 \\
2.4 & 20 & 4 & 80 & 0 & 20 \\
2.5 & 20 & 2 & 40 & 50 & 10 \\
2.6 & 20 & 4 & 40 & 50 & 10 \\
2.7 & 20 & 4 & 40 & 50 & 10 \\
2.8 & 20 & 5.5 & 40 & 50 & 10 \\
2.9 & 20 & 2 & 0 & 83.4 & 16.6 \\
2.10 & 40 & 1 & 80 & 0 & 20 \\
\hline
\end{tabular}

\section{ANALYTICAL PROCEDURES}

Analytical procedures included analysis of the biogas composition, solids determination with percent total solids and volatile solids destruction, volatile fatty acids (VFA) concentration, $\mathrm{pH}$, alkalinity, total ammonia nitrogen $\left(\mathrm{NH}_{3}+\mathrm{NH}_{4}{ }^{+}\right)$and $\mathrm{C}: \mathrm{N}$ ratio. Biogas composition was determined weekly using a gas chromatograph, and the volume of gas was measured daily. These two measurements were used to determine methane yield. Volatile solids destruction was measured weekly and used for mass balances. VFA, $\mathrm{pH}$, alkalinity, and ammonia nitrogen concentrations were used to determine digester stability and assess digester health. VFA and ammonia nitrogen were measured weekly, while alkalinity was measured every other day, and the $\mathrm{pH}$ was measured daily. The C: $\mathrm{N}$ ratio 
was measured weekly and was used in mass balance analysis. The daily volume of digester effluent available determined the frequency of analytical tests.

\section{BIOGAS COMPOSITION}

The methane concentration in the biogas was determined using a gas chromatograph (SRI 8610, Torrance California) with a thermal conductivity detector and a six-foot concentric packed column that contains an inner and outer column (Alltech CTR I, Deerfield Illinois). The outer column consisted of a $6.35-\mathrm{mm}$ diameter activated molecular sieve, and the inner column consisted of an eighth of an inch diameter tube filled with a proprietary porous polymer mixture. Ultra-high purity helium was used as the carrier gas at a flow rate of $16 \mathrm{~mL} / \mathrm{min}$. The operating temperature was $45^{\circ} \mathrm{C}$, and each injected sample contained a gas volume of $1 \mathrm{~mL}$. The sample run time was 17 minutes. The gas chromatograph was located in the same room as the digesters and sampling consisted of removing a $1-\mathrm{mL}$ sample from the septa on the gas collector and walking the sample 5 meters to the gas chromatograph where it was promptly injected.

\section{SOLIDS CONCENTRATION}

Solids concentrations were measured as mass per volume using a 3-mL syringe to take a 3-mL subsample of digester feed or effluent, in an altered form of Standard Method 2540B (APHA 2005). Samples were dried to a constant weight at $105{ }^{\circ} \mathrm{C}$ and then ashed at $525^{\circ} \mathrm{C}$. Total solids and volatile solids destruction in the digesters was calculated using the following equations: 
$\begin{array}{lr}\operatorname{TSD}(\%)=100 \times\left[1-\left(\frac{T S E}{T S F}\right)\right] & \text { Equation } 1 \\ \operatorname{VSD}(\%)=100 \times\left[1-\left(\frac{V S E}{T S F \times \% V S}\right)\right] & \text { where, Equation 2 }\end{array}$

TSD $=$ Total solids destruction in percent

TSE $=$ Total solids of the effluent in $\mathrm{g} / \mathrm{L}$

$\mathrm{TSF}=$ Total solids of the feed in $\mathrm{g} / \mathrm{L}$

VSD $=$ Volatile solids destruction in percent

VSE $=$ Volatile solids in the effluent in $\mathrm{g} / \mathrm{L}$

$\% \mathrm{VS}=$ Percent of total solids that is volatile solids in the feed

\section{VOLATILE FATTY ACIDS, pH, ALKALINITY, AND AMMONIA NITROGEN}

Volatile fatty acids, $\mathrm{pH}$, alkalinity and ammonia nitrogen were determined using standard methods (APHA, 2005). Volatile fatty acids were determined per Method 5560 B using the chromatographic separation method for organic acids (APHA 2005). pH was determined using a calibrated Mettler Toledo Inlab 4B pH probe with a gel type electrode, and alkalinity was determined per Method 2320B by titrating with $0.50-\mathrm{N}$ $\mathrm{H}_{2} \mathrm{SO}_{4}$ to $\mathrm{pH} 4.5$ (APHA 2005). Ammonia nitrogen was determined per Method 4500 using the ammonia selective electrode method and a Thermofisher Scientific Orion 9512 electrode (APHA 2005). 


\section{C:N RATIO}

The C:N ratio was determined using a Vario-Max Elementar Carbon and Nitrogen Analyzer using NIST certified tomato leaves as the carbon standard and glutamic acid as the nitrogen standard. These standards bracketed the $\mathrm{C}: \mathrm{N}$ ratio of the digester feeds, with a C:N ratio of 5:1 for glutamic acid and 12:1 for tomato leaves. On a weekly basis, 20$\mathrm{mL}$ samples of digester feed and effluent were prepared by adding concentrated sulfuric acid to the sample until the $\mathrm{pH}$ dropped below 4.5, which ensured that ammonia did not volatilize during drying of the samples. Each sample was then dried at $55^{\circ} \mathrm{C}$ for three days and ground into a powder with a mortar and pestle. Each sample was then stored in a desiccator until enough samples accumulated to fill the instrument auto sampler (i.e., sixty samples). Using catalytic tube combustion at $1200^{\circ} \mathrm{C}$, the Variomax oxidized carbon and nitrogen compounds. Specific absorption columns then separated C and $\mathrm{N}$ prior to being analyzed in a thermal conductivity detector, which was used to quantify the carbon and nitrogen in each sample.

\section{MODEL DEVELOPMENT}

The multiple regression models were developed using the linear least squares method using Minitab 16 (Minitab, State College Pennsylvania). Descriptive models were developed to explain, in graphical and equation form, the results of Experiments 1 and 2. The models characterize digester results such as yield, volatile solids destruction, and ammonia nitrogen, alkalinity, and volatile fatty acids concentrations for digestion of algae, or algae and sludge, or algae sludge and food waste. Extended and a compact descriptive models were developed. The extended models included all parameters 
including those that were not statistically significant $(\mathrm{p}>0.05)$, given the data available. Using backwards elimination, the compact models only included parameters that were statistically significant $(\mathrm{p}<0.05)$. The model is not intended for characterizing digesters fed food waste alone. The models describe only the limited conditions used in the present study.

Different digesters had diverse ranges of variability so steady state had to be defined using standard deviations. The data used in model development were from stable digestion periods defined as the contiguous time period when the following conditions were met: (1) solids concentrations varied less than one standard deviation from the mean solids concentration, (2) ammonia nitrogen concentrations and volatile fatty acid concentrations varied less than two standard deviations from their mean value, and (3) for biogas production and yield, $\mathrm{pH}$, and alkalinity, no more than one value fell outside two standard deviations of their mean. The mean values for comparison were determined by averaging all the data for each constituent after 22 days of operation, which was the sample date collected nearest the end of the first residence time. For duplicate digesters the steady state periods selected were those that overlapped in time, with the allowance of one week before or after the overlapping period in order to increase the number of included data points.

Periods outside the selected steady state periods used for the models usually exhibited stable digestion with the $\mathrm{pH}$ remaining in the healthy range of 6.6-7.6 defined by McCarty (1964), and continued production of biogas without significant dips that may have indicated process upset. Generally, the stable digestion periods exceeded the 
selected steady state period used in the model, and for most digesters encompassed the entire digester operation period.

An unstable digester was a digester that required intervention to prevent culture crash (i.e., a pH that dropped below 6.5 and/or a significant decrease in biogas production). Other characteristics of impending instability or culture crash include decreasing $\mathrm{pH}$ and alkalinity, an increase in volatile fatty acids, and a decrease in biogas production. Methods of intervention included adding alkalinity in the form of $\mathrm{NaOH}$ and reinoculating the digester with San Luis Obispo water Reclamation Facility digester three effluent. In order to record natural digestion variations, and observe culture crash intervention was not performed until the digester stopped producing biogas. The periods of operationally unstable operation were not included in the model data set. 


\section{RESULTS}

In most of the digesters, stable digestion was reached at between 1.5 and 3 residence times following the start of operation. In most digesters, solids concentration reached steady state later than ammonia, volatile fatty acids, $\mathrm{pH}$, alkalinity, and methane yield. This delay in solids concentration steady state was pronounced in digesters with high algae content in their feed and high organic loading rates. Although digesters fed 100\% algae did not crash, their output variables generally varied more from measurement to measurement than digesters fed less or no algae. Higher organic loading rates also lead to higher variability between measurements.

Figures 4 through 12 are provided as examples of digester response variable values. Model steady state periods are shown for each digester. Digester 2.2 was chosen as an example because it was fed $100 \%$ algae at a high loading rate of $4 \mathrm{~g}$ VS/ L-d. Digester 1.5 was fed $100 \%$ sludge at a rate of $2 \mathrm{~g} \mathrm{VS} / \mathrm{L}-\mathrm{d}$ and was chosen to provide comparison between sludge and algae digestion. Digester 2.8 was fed $50 \%$ food waste, $40 \%$ algae and, $10 \%$ sludge at a rate of $5.5 \mathrm{~g} \mathrm{VS} / \mathrm{L}-\mathrm{d}$ and was chosen to show a digester with a high organic loading rate that caused process instability.

Returning to Digester 2.2 (Figure 4), it showed the characteristics of a stable digester, with relatively stable values over the duration of the experiment for alkalinity, $\mathrm{pH}$, volatile fatty acids, and ammonia nitrogen, following a start-up period lasting two residence times (40 days). Over the duration of the experiment Digester 2.2 exhibited the characteristics of a healthy digester. For the same digester, after one residence time or 20 days, the biogas production and methane yield values appear to have stabilized (Figure 
5). The dip in biogas production from about Day 45 to Day 60 (Figure 5) was likely caused by a slow and steady decrease in volume caused by inadvertent drips and small spills during feeding, which also occurred in Digesters 2.1, 2.1 2.4, and 2.6. This 10-15\% decrease in the total digester volume caused the organic loading rate to increase to the point that it apparently caused a slight drop in $\mathrm{pH}$, alkalinity, and biogas production. Digester health parameters stabilized after the volume was increased with algae feed to the intended $0.5 \mathrm{~L}$. The problem was avoided for the remainder of the experiment by more careful feeding and adding a few extra milliliters of feed each time digested material was removed to make up for any drips.

For Digester 2.2 effluent, solids concentration reached relative stability after 2.4 residence times or 48 days (Figure 6). Interestingly, solids concentration for all digesters being fed $100 \%$ algae continued to increase, and at the end of three hydraulic residence times, still showed a slight increase in solids concentration from week to week (Figure 6). This long term solids accumulation indicates the low extent of algal volatile solids destruction. 


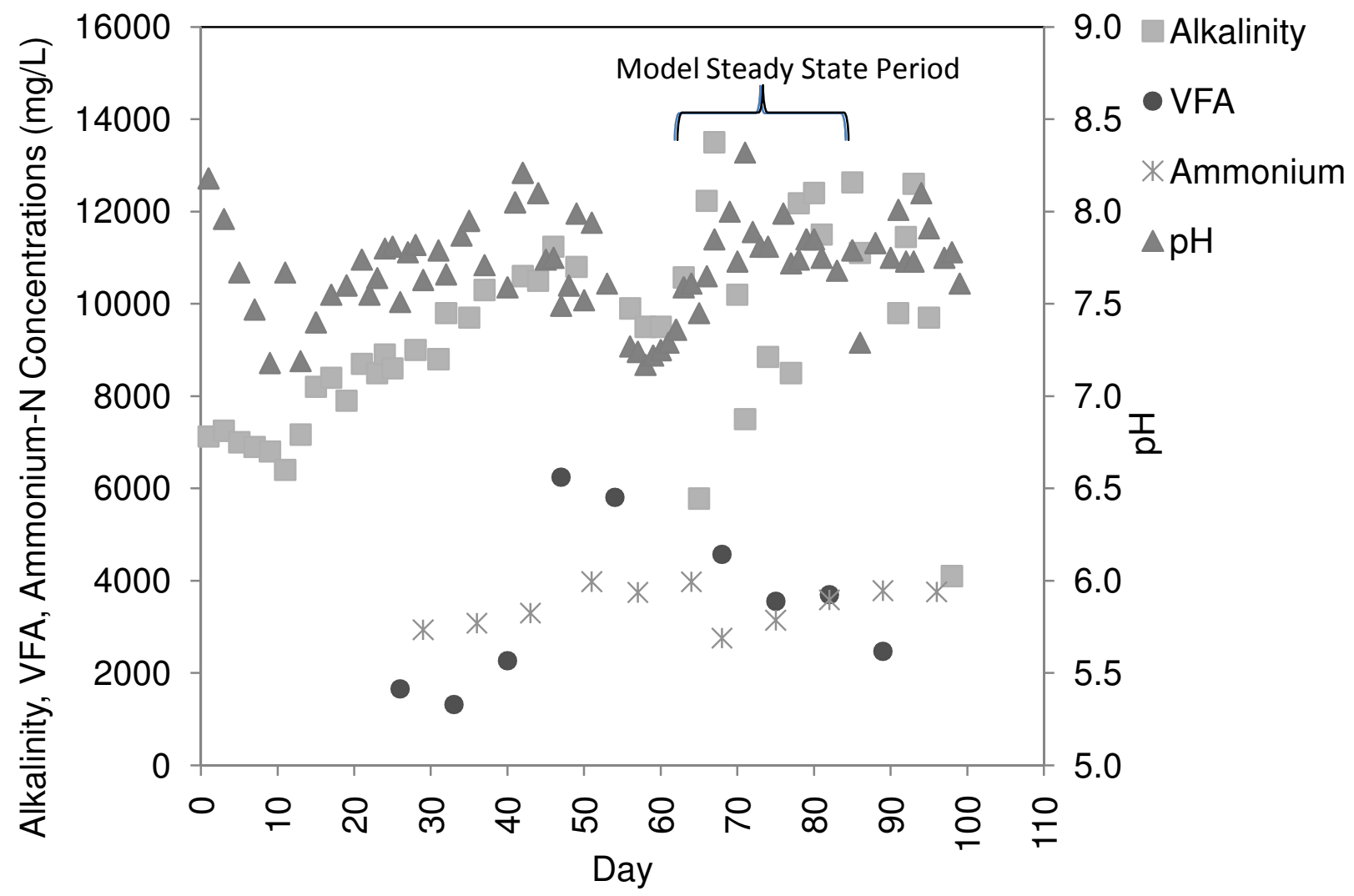

Figure 4: Digester effluent characteristics over time for Digester 2.2 (100\% algae feed at $4 \mathrm{~g} \mathrm{VS} / \mathrm{L}-\mathrm{d}$ and a 20-day residence time) are shown as an example of the data collected for all digesters in the study. Using the criteria described in this text, the model steady state period for this digester was determined to be Days 62-83. The decreases in $\mathrm{pH}$, and alkalinity during Days 45 through 60 were caused by inadvertent declining of the digester volume. 


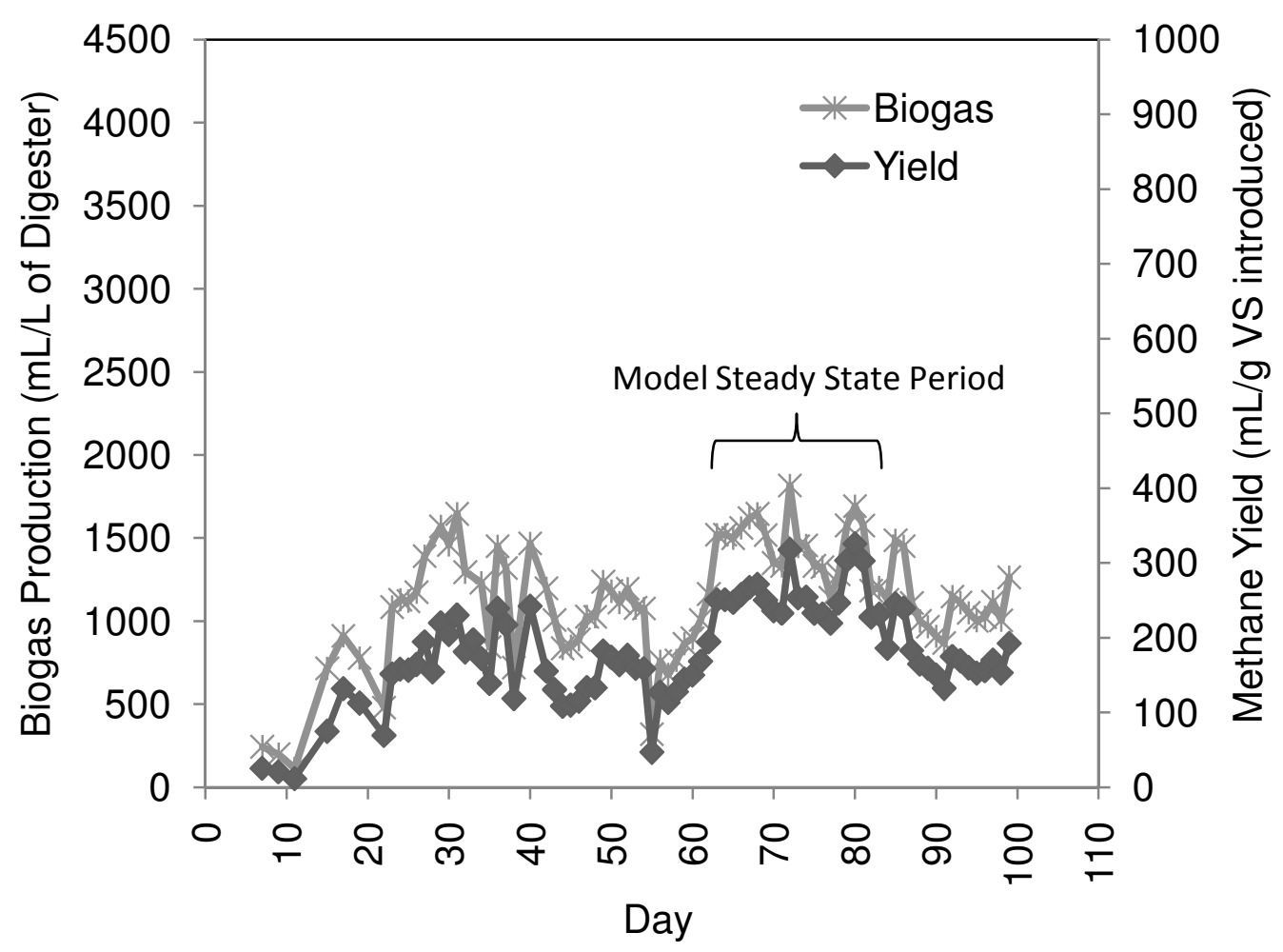

Figure 5: Digester 2.2 (100\% algae feed at $4 \mathrm{~g} \mathrm{VS/L-d} \mathrm{and} \mathrm{a} \mathrm{20-day} \mathrm{residence} \mathrm{time)}$ biogas production and methane yield over time. The dip in biogas production from Day 40-55 was probably caused by the gradually decreasing digester volume described in the text. This dip at Day 55 led to exclusion of these data using the steady state selection criteria. Additionally, many other yield data points beyond the model steady state period met the criteria but were excluded because solids concentrations or digester effluent characteristics were not at steady state at that time. 


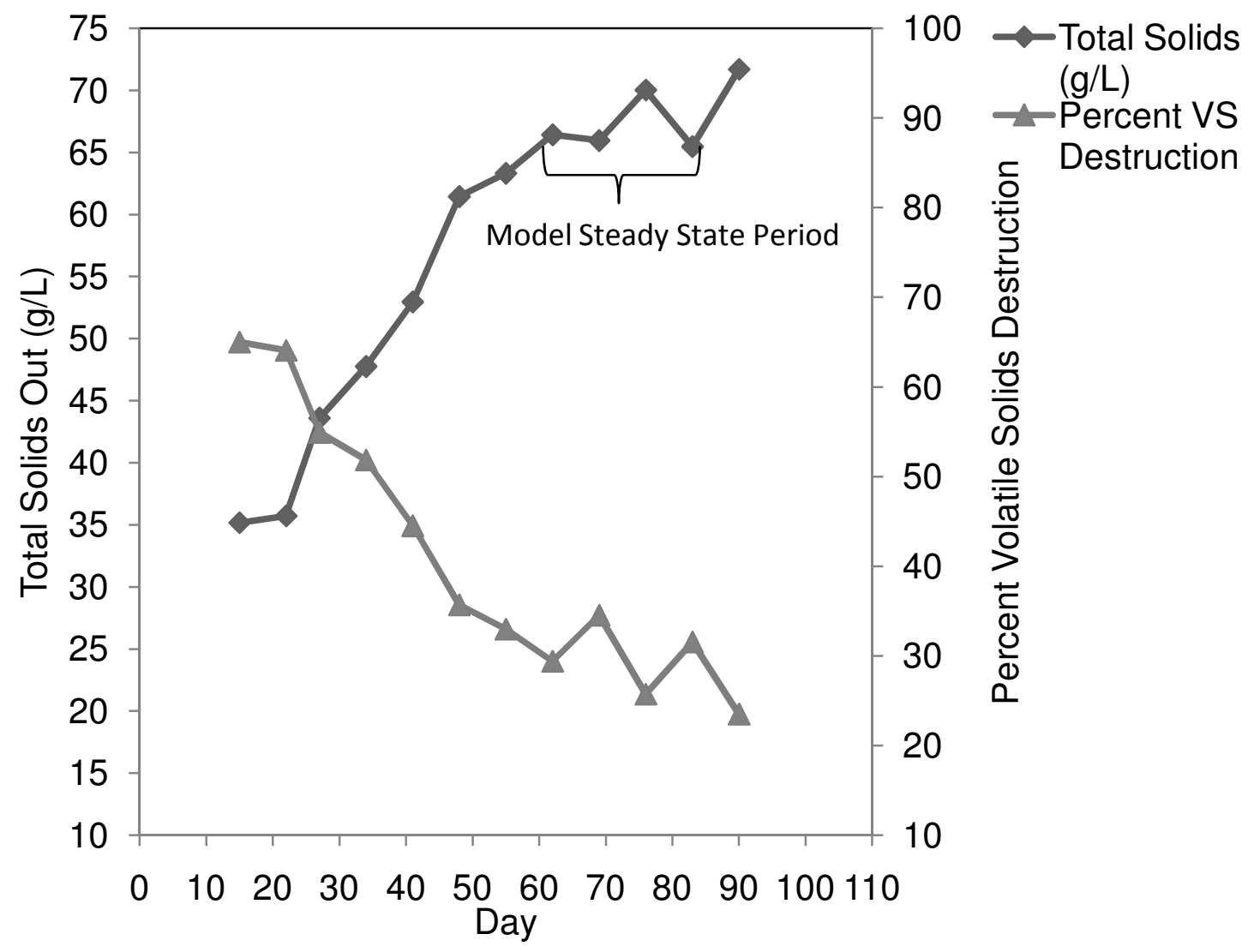

Figure 6: Digester 2.2 (100\% algae feed at $4 \mathrm{~g}$ VS/L-d and a 20-day residence time) solids data. Total solids concentration in the effluent appeared to stabilize around Day 48.

The most consistently stable digester for all parameters was Digester 1.5, which acted as the sludge-only control digester. This sludge control digester was fed $100 \%$ sludge at a rate of $2 \mathrm{~g} \mathrm{VS} / \mathrm{L}$-day with a residence time of 20 days. Alkalinity, $\mathrm{pH}$, volatile fatty acids, and ammonia nitrogen concentrations stabilized within half a residence time, and biogas production and methane yield stabilized within one residence time (Figure 7 and 8). Over the duration of the experiment, total solids concentration in the digester decreased but experienced less pronounced decreases at 1.5 residence times (Figure 9). Generally, this digester was the most robust and stable digester. 


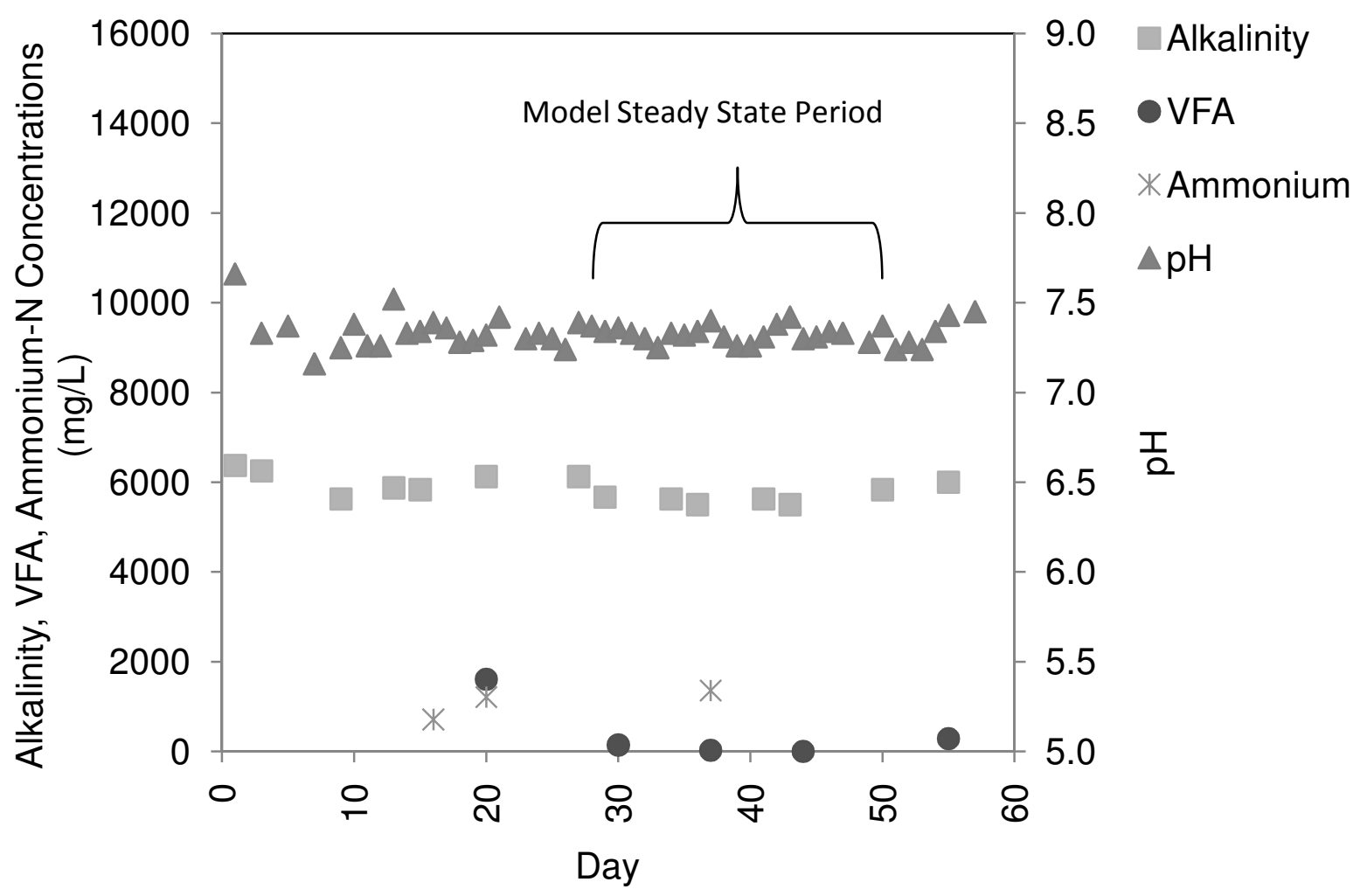

Figure 7: Digester effluent characteristics over time for Digester 1.5 (100\% sludge feed at $2 \mathrm{~g} \mathrm{VS} / \mathrm{L}-\mathrm{d}$ and a 20-day residence time) are shown as an example of the most digester over time. In this case, the model steady state period was determined to be Day 29-50. 


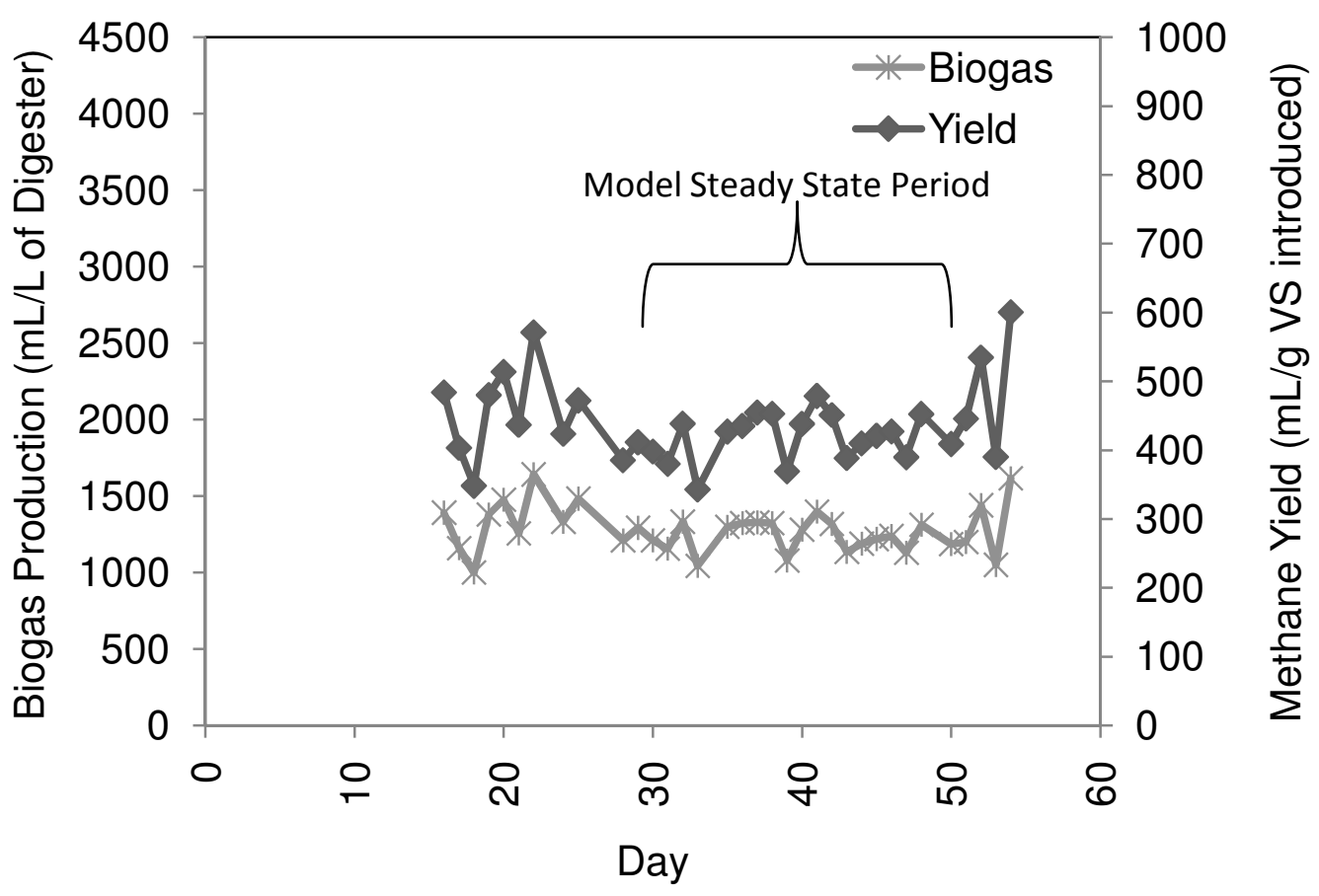

Figure 8: Digester 1.5 (100\% sludge feed at $2 \mathrm{~g} \mathrm{VS} / \mathrm{L}-\mathrm{d}$ and a 20-day residence time) biogas production and methane yield over time. This digester showed the least variation for all measurements over time. 


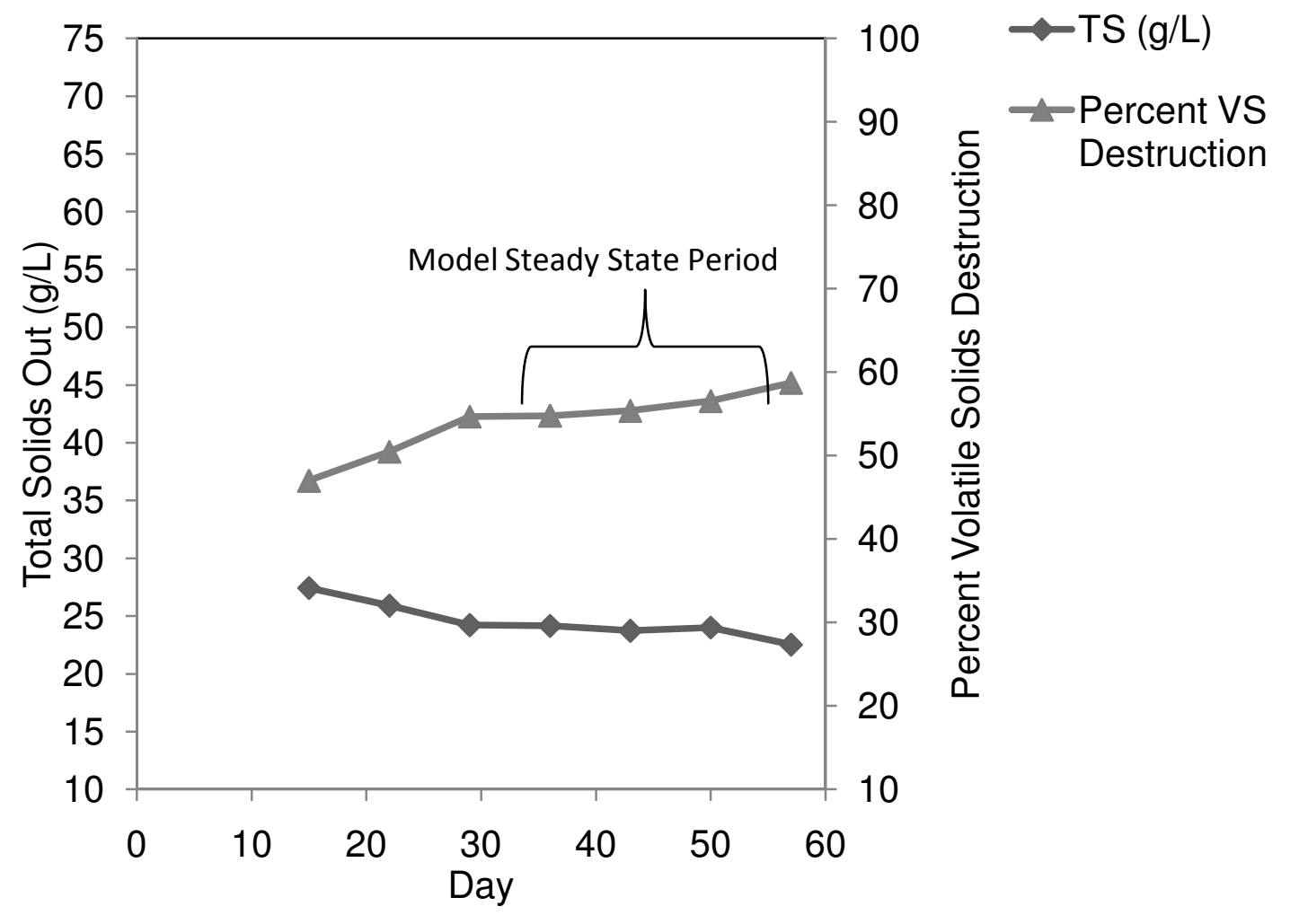

Figure 9: Digester 1.5 (100\% sludge feed at $2 \mathrm{~g} \mathrm{VS/L-d} \mathrm{and} \mathrm{a} \mathrm{20-day} \mathrm{residence} \mathrm{time)}$ solids data. Total solids concentration in the digester effluent decreased slightly for the duration of the experiment while volatile solids destruction increased slightly. This is in direct contrast to the algae digesters; however, the slope of decreasing total solids is significantly less than the slope of increasing total solids in the algae digesters.

Digester 2.8 was an unstable digester in terms of volatile fatty acids, $\mathrm{pH}$, alkalinity, biogas production, and to lesser extent solids over the duration of the experiment (Figures $10,11,12)$. Digester 2.8 was fed $40 \%$ algae, $10 \%$ sludge, and $50 \%$ food waste at a rate of $5.5 \mathrm{~g} \mathrm{VS} / \mathrm{L}$-day with a residence time of 20 days. The high organic loading rate of 5.5 g VS/L-day was probably the primary factor that caused digester instability. This was the highest organic loading used in the entire experiment and was predicted to be unstable. The high proportion of food waste in the feed gave the digester a relatively high C:N ratio, so ammonia inhibition most likely did not contribute to instability. 
In Digester 2.8, $\mathrm{pH}$, alkalinity, volatile fatty acids, and ammonia nitrogen concentrations did not remain stable (Figure 10). After the first residence time until Day 47 the digester exhibited generally stable characteristics; however, after this period the $\mathrm{pH}$ dropped and the volatile fatty acid concentration increased to over $10,000 \mathrm{mg} / \mathrm{L}$. When the digesters stopped producing biogas around Day 60, the digester was re-inoculated with SLOWRF Digester 3 effluent, and the $\mathrm{pH}$ was adjusted with sodium hydroxide to a $\mathrm{pH}$ of 7.0. Despite a short period of recovery, the $\mathrm{pH}$ dropped to below 6.5 by the end of the experiment, leading to poor methane production. The high but steady ammonia nitrogen concentration was similar to the concentrations in other healthy digesters (Digesters 2.1, 2.2), which indicates that ammonia inhibition was probably not a major factor in the instability. The high concentration of volatile fatty acids indicated that organic loading was most likely the major cause of instability.

Despite the relatively instable operational parameters, several periods of prolonged stable biogas production were observed for Digester 2.8 (Figure 11). From Day 41 to Day 55, the biogas production and methane yield were relatively stable. Decreases in biogas production corresponded well with decreases in $\mathrm{pH}$, but only once the $\mathrm{pH}$ measured less than 6.5. The digester performed fairly well in terms of biogas production and yield as long as the $\mathrm{pH}$ remained above 6.5 ; therefore, this digester could be expected to perform stably with a high yield with continual $\mathrm{pH}$ adjustment and alkalinity addition. Additionally, the solids concentration varied much less over the duration of the experiment when compared to $\mathrm{pH}$, alkalinity, and methane yield (Figure 12). 
Over the entire experiment, only Digester 2.8 required re-inoculation. Data from the unstable period and from several weeks following the re-inoculation period were not used in the model. Digester 2.8 was revived with re-inoculation and base addition in order to confirm digester instability and failure, which was most likely caused by a loading rate that lead to volatile fatty acid accumulation and toxicity. Revival also showed that the digester might be maintained with regular doses of alkalinity; however, regular doses of alkalinity were not added to this digester so yield numbers do not necessarily reflect maximum digester yields. Despite long periods of instability, a steady state period was identified as per the model steady state criteria. 


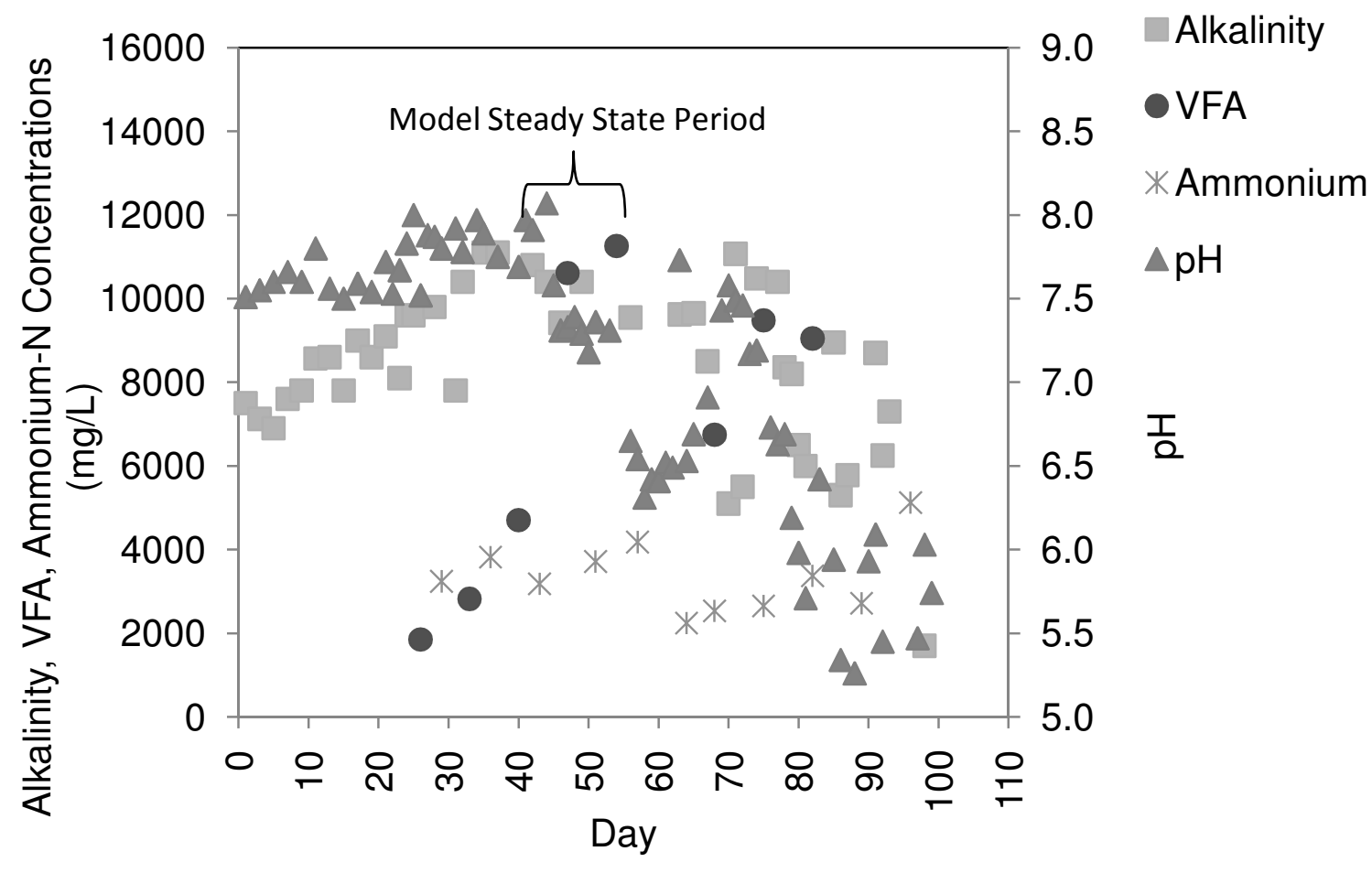

Figure 10: Digester effluent characteristics over time for Digester 2.8 (40\% algae, 50\% food waste, and $10 \%$ sludge feed at $5.5 \mathrm{~g} \mathrm{VS} / \mathrm{L}-\mathrm{d}$ and a 20-day residence time). In this case, the model steady state period was determined to be Day 41-55. Although this steady state period shows a steadily decreasing $\mathrm{pH}$ and high volatile fatty acids values the alkalinity values remain fairly stable and the values meet the steady state criteria.

Although earlier periods show more stable $\mathrm{pH}$ and volatile fatty acids, the period after the first residence time was particularly unstable in terms of biogas production and yield (Figure 10). 


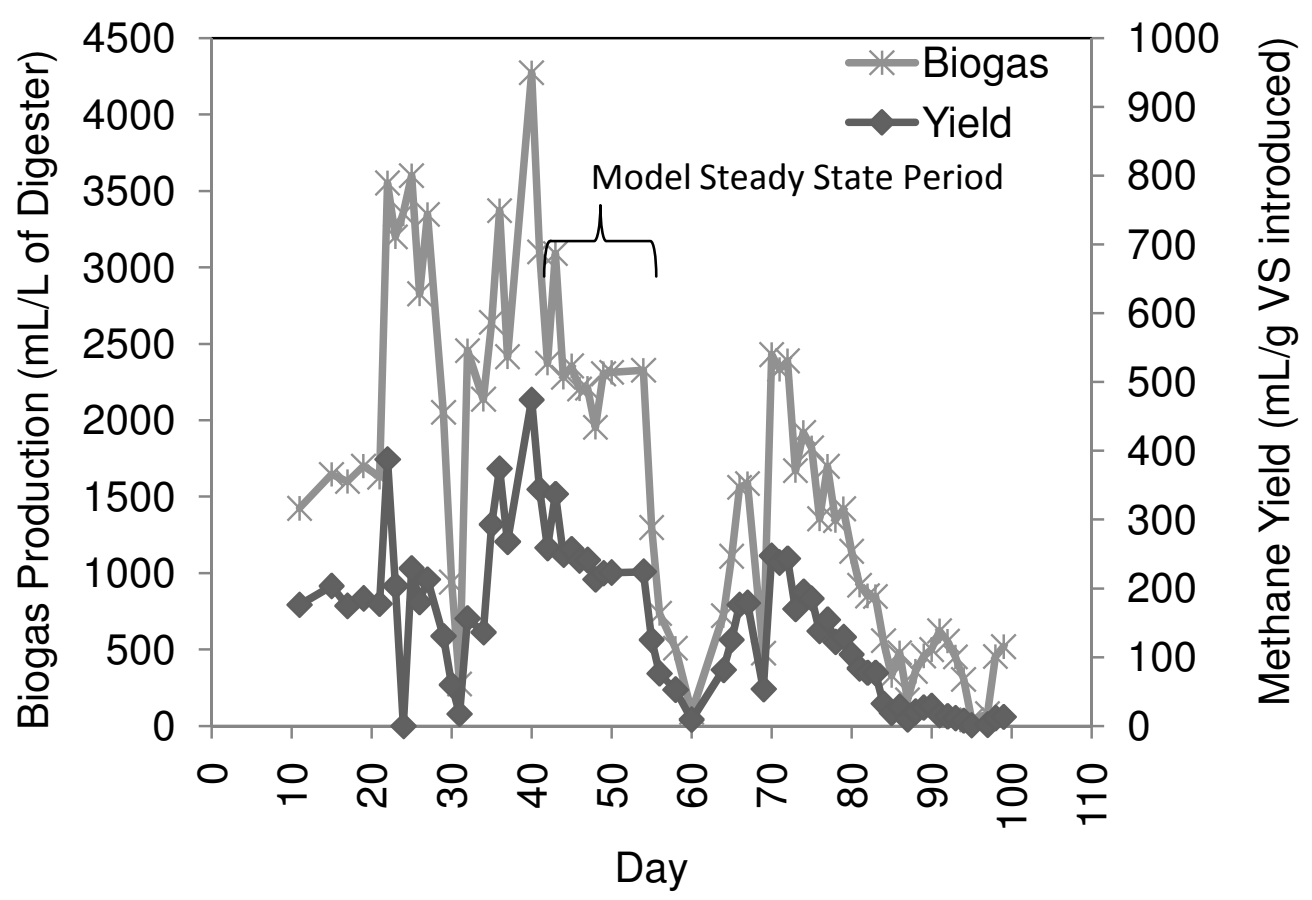

Figure 11: Digester 2.8 (40\% algae, 50\% food waste, and $10 \%$ sludge feed at $5.5 \mathrm{~g}$ VS/L$\mathrm{d}$ and a 20-day residence time) biogas production and methane yield over time. The model steady state period of Day 41-55 avoids any extreme dips or peaks in biogas production and yield. By Day 60, Digester 2.8 experienced complete digester collapse, and despite the reintroduction of methanogens and a $\mathrm{pH}$ adjustment, the digester was unable to maintain a steady $\mathrm{pH}$ and biogas production for the remainder of the experiment. Continuous or semi continuous alkalinity addition would probably be needed to maintain healthy digestion with these feeds at this high loading rate. 


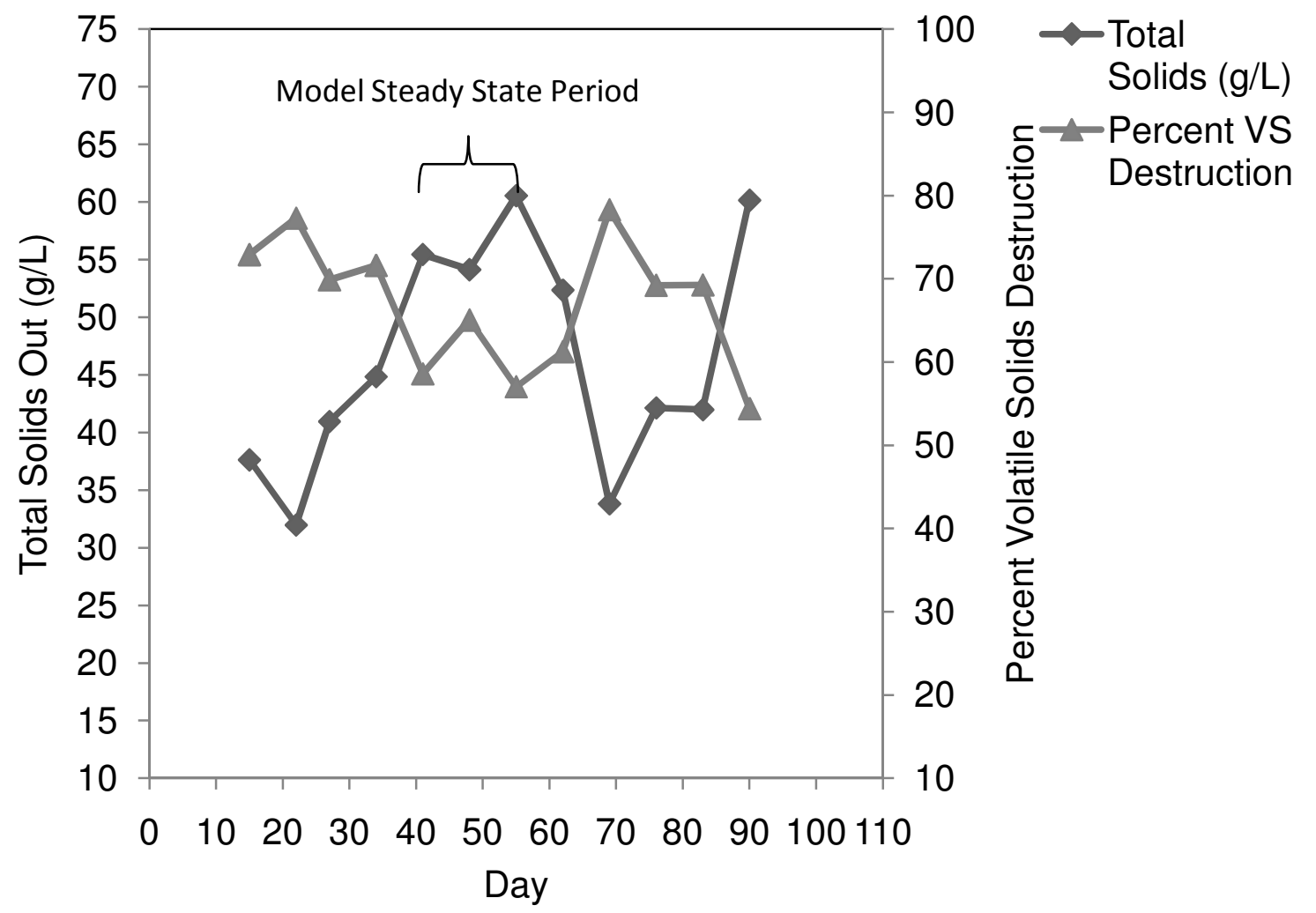

Figure 12: Digester 2.8 (40\% algae, $50 \%$ food waste, and $10 \%$ sludge feed at $5.5 \mathrm{~g} \mathrm{VS} / \mathrm{L}$ $\mathrm{d}$ and a 20-day residence time) solids data. The solids data reflects the digester instability with digester solids increasing and peaking right before culture crash.

\section{INFLUENCE OF FEED COMPOSITION, ORGANIC LOADING RATE AND RESIDENCE TIME}

The multivariate linear models presented in the following sections indicate the effect of the independent variables of fraction of algae in the feed, fraction of food waste in the

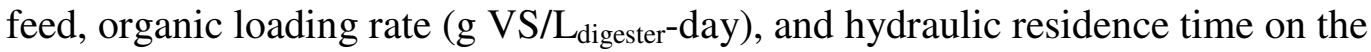
dependent variables of alkalinity concentration, ammonium concentration, volatile fatty acid concentration, volumetric methane yield, percent methane in the biogas, and percent volatile solids destruction. For all the digesters, data points for the models were chosen by identifying intersecting periods of stable gas, solids and operational parameters per the 
criteria described in the methods section. For the periods of stable digestion, all the data points were averaged to provide a single representative value for each dependent variable. From these models and the p-value given for each variable, compact models were developed from variables displaying a p-value greater than 0.05. In addition, single equation models of variables related to culture stability such as total ammonia nitrogen, volatile fatty acids, and total alkalinity concentrations were developed.

\section{ALGAE CONTENT}

For the four digesters fed $100 \%$ algae, the methane yield ranged from $0.21-0.26 \mathrm{~L} / \mathrm{g}$ VS (Table 3). Increasing the organic loading rate in the $100 \%$ algae digesters from 2 to $4 \mathrm{~g}$ VS/L-day did not result in a significant change in methane yield. The four digesters fed $80 \%$ algae had yields ranging from $0.24-0.30 \mathrm{~L} / \mathrm{g} \mathrm{VS}$ in. Digesters containing $60 \%$ algae in the feed gave yields ranging from $0.36-0.36 \mathrm{~L}_{\mathrm{g} \mathrm{VS}}$. Digesters containing $40 \%$ algae in the feed gave yields ranging from $0.25-0.40 \mathrm{~L} / \mathrm{g} \mathrm{VS}_{\mathrm{in}}$, and $20 \%$ algae in the feed gave a yield of $0.40 \mathrm{~L} / \mathrm{g} \mathrm{VS}_{\mathrm{in}}$. Finally, the yields for the two digesters fed no algae were 0.42 and $0.68 \mathrm{~L} / \mathrm{g} \mathrm{VS}_{\mathrm{in}}$. The percent of algae in the feed decreased the methane yield in a linear fashion independent of other variables such as residence time, remaining feed composition, and organic loading rate (Figure 13). Algae sludge co-digestion showed no synergistic effect, as was noted in the Samson and LeDuy study (1987). The highest methane yield was observed when there was no algae biomass in the digester feed, and the lowest methane yield was observed when the digester feed was completely composed of algae. 
Considering only different algae contents in the feed, three linear relationships are apparent in the dependent variables (Figure 13). The amount of methane in the biogas, or biogas quality, increased slightly with increasing algae in the feed (Figure 13). Higher algae content in the feed corresponded to lower volatile solids destruction. The retention of volatile solids in algae digesters, even with optimum $\mathrm{pH}$, ammonia nitrogen, and volatile fatty acid concentrations, indicates that much of the volatile solids remained inaccessible to the anaerobic bacteria. This suggests that algae retained much of the volatile solids associated with their cell wall their cell walls and most of the biogas production may have come from dissolved volatiles in solution, wastewater carbon, algae with weaker cell walls such as euglena and diatoms, and old deteriorating cells.

When different loading rates, residence times, and feeds are introduced into the regression data set (Figure 14), the relationships are similar, but the r-squared values decrease. Including other loading rates, residence times and food waste digesters results in a slightly larger negative slope of methane yield and volatile solids destruction with higher algae content in the feed; however, the overall relationship of lower volatile solids destruction, and methane yield with higher algae content in the feed was maintained (Figure 14). 


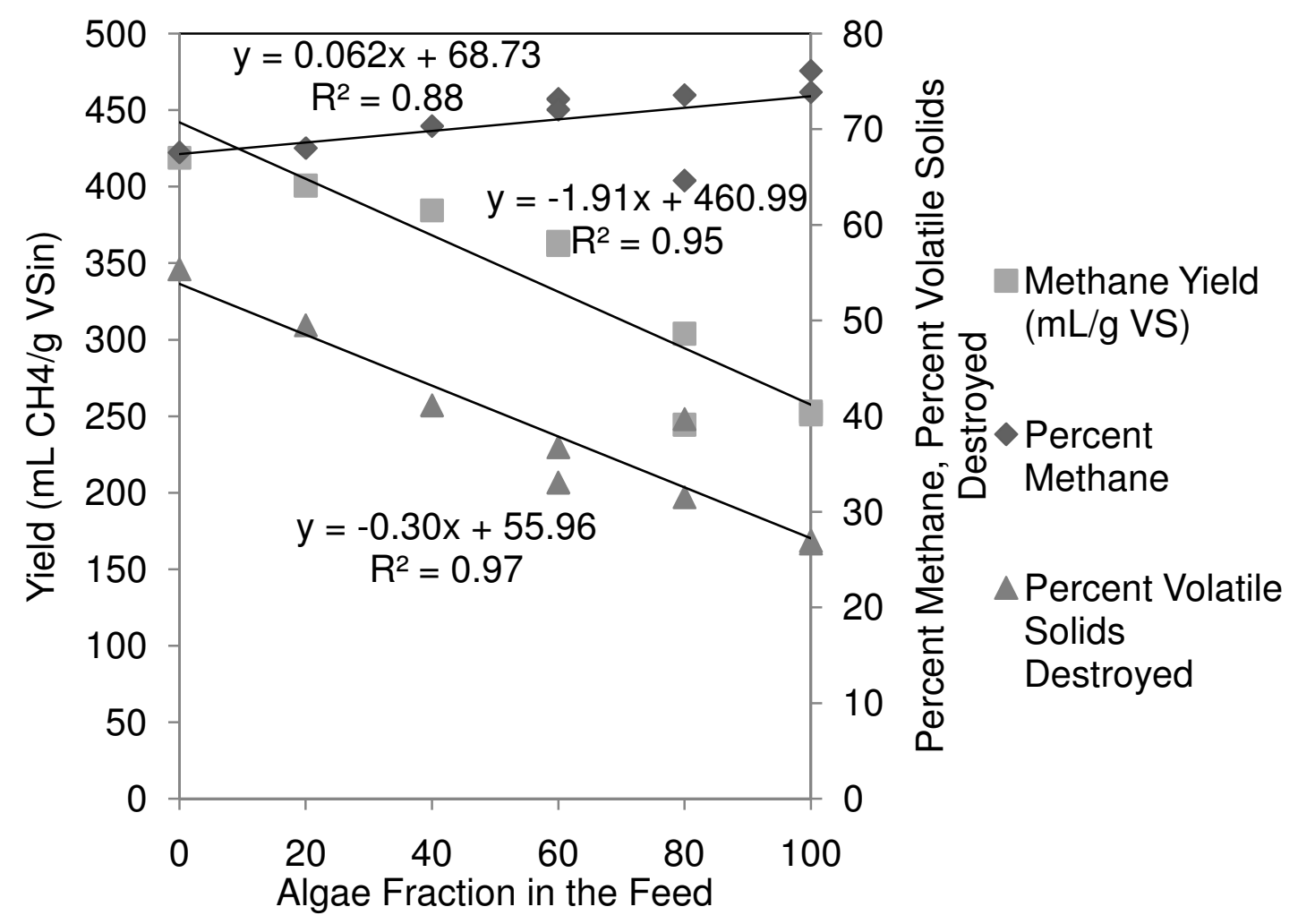

Figure 13: Effect of algae content in the feed on methane yield, percent of volatile solids destroyed and methane content in the biogas for digesters fed only algae and sludge at a rate of $2 \mathrm{~g}$ VS/L-day and a 20-day residence time. Duplicate digesters are not averaged. 


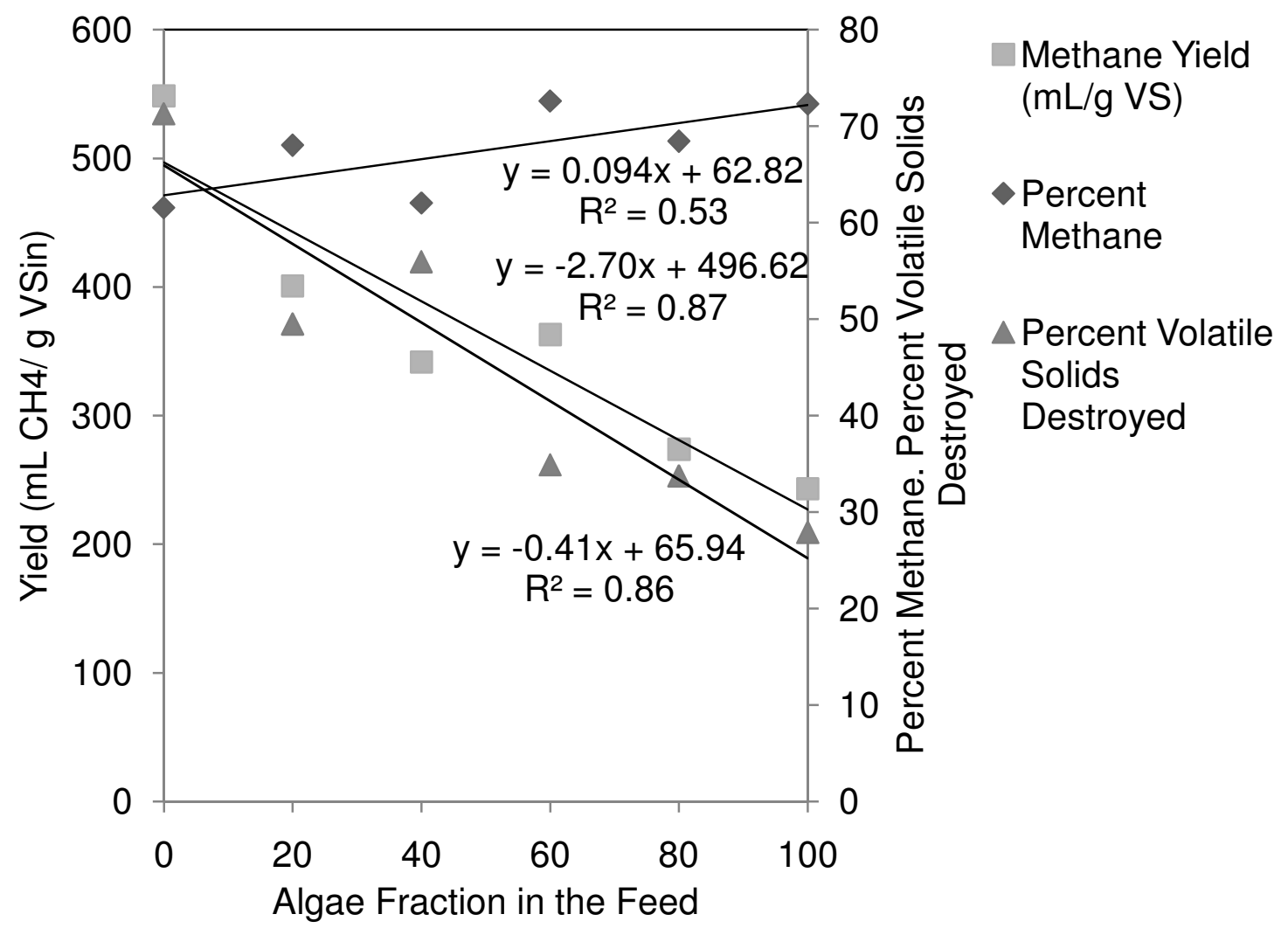

Figure 14: The effect of algae content in the feed on methane yield, percent of volatile solids destroyed and biogas quality when various residence times and loading rates are included in the data set. Values for digesters with the same algae content in the feed were averaged. Averaging the values diminishes the effect of some influential variables such as food waste and allows the effect of algae feed to be seen independently of the other variables.

\section{FOOD WASTE CONTENT}

Food waste was used at two different concentrations in Experiment 2 (Table 3). Digester 2.9 was fed $83.4 \%$ food waste with the remainder of the feed consisting of sludge at rate of $2 \mathrm{~g} \mathrm{VS/L-day} \mathrm{and} \mathrm{a} \mathrm{20-day} \mathrm{residence} \mathrm{time.} \mathrm{This} \mathrm{digester} \mathrm{produced} \mathrm{the} \mathrm{highest} \mathrm{yield} \mathrm{of}$ both experiments of $0.68 \mathrm{~L} \mathrm{CH}_{4} / \mathrm{g} \mathrm{VS}_{\text {in }}$ and vastly exceeded the next closest digester (1.5) which was the $100 \%$ sludge-fed digester with a yield of $0.42 \mathrm{~L} \mathrm{CH}_{4} / \mathrm{g} \mathrm{VS}_{\text {in }}$ at a rate of $2 \mathrm{~g} \mathrm{VS/L-day} \mathrm{and} \mathrm{a} \mathrm{20-day} \mathrm{residence} \mathrm{time} \mathrm{(Table} \mathrm{3).} \mathrm{Four} \mathrm{other} \mathrm{digesters} \mathrm{in}$ 
Experiment 2 were fed 50\% food waste, $40 \%$ algae and $10 \%$ sludge. Digester 2.5 was fed this mixture at a rate of $2 \mathrm{~g} \mathrm{VS/L-day} \mathrm{and} \mathrm{a} \mathrm{20-day} \mathrm{residence} \mathrm{time,} \mathrm{while} \mathrm{Digesters}$ 2.6 and 2.7 were duplicates set at $4 \mathrm{~g}$ VS/L-day and a 20-day residence time. Finally, Digester 2.8 was fed the same feed combination at a rate of $5.5 \mathrm{~g} \mathrm{VS/L-day} \mathrm{and} \mathrm{a} \mathrm{20-day}$ residence time. Due to the high organic loading, Digester 2.8 was largely unstable. Methane yield at $50 \%$ food waste ranged from $0.25-0.40 \mathrm{~L} \mathrm{CH}_{4} / \mathrm{g} \mathrm{VS}_{\text {in }}$.

Generally, higher food waste content in the feed improved digestion yields and volatile solids destruction. Combining all results for $0 \%$ food waste in the feed, $50 \%$ food waste in the feed, $83.4 \%$ food waste in the feed showed that higher food waste content led to higher methane yields and greater volatile solids destruction (Figure 15). For the lower organic loading rates, the higher the food waste content in the digester feed, the better the digester performed. Removing Digester 2.8 from the average data set for $50 \%$ algae in the feed increased the r-squared of the yield value to 0.76 and gave an equation of Yield $=4.18 \mathrm{x}+262.67$. Removing all the digesters loaded at $4 \mathrm{~g}$ VS/L-d further improves the r-squared value.

Not enough data were available to determine the presence or lack of a synergistic effect caused by using food waste. The methane yield in the digester fed $83.4 \%$ food waste and $16.6 \%$ sludge (Digester 2.9) was 16\% greater than the yield for the digester fed 100\% sludge (Digester 1.5); however, it is unlikely that these results show a synergistic effect because the food waste used most likely had higher energy content than the sewage sludge. The high yield at $83.4 \%$ food waste was most likely not due to synergy but due to the abundance of an energy-rich substrate and a more favorable $\mathrm{C}: \mathrm{N}$ ratio of 17:1. 


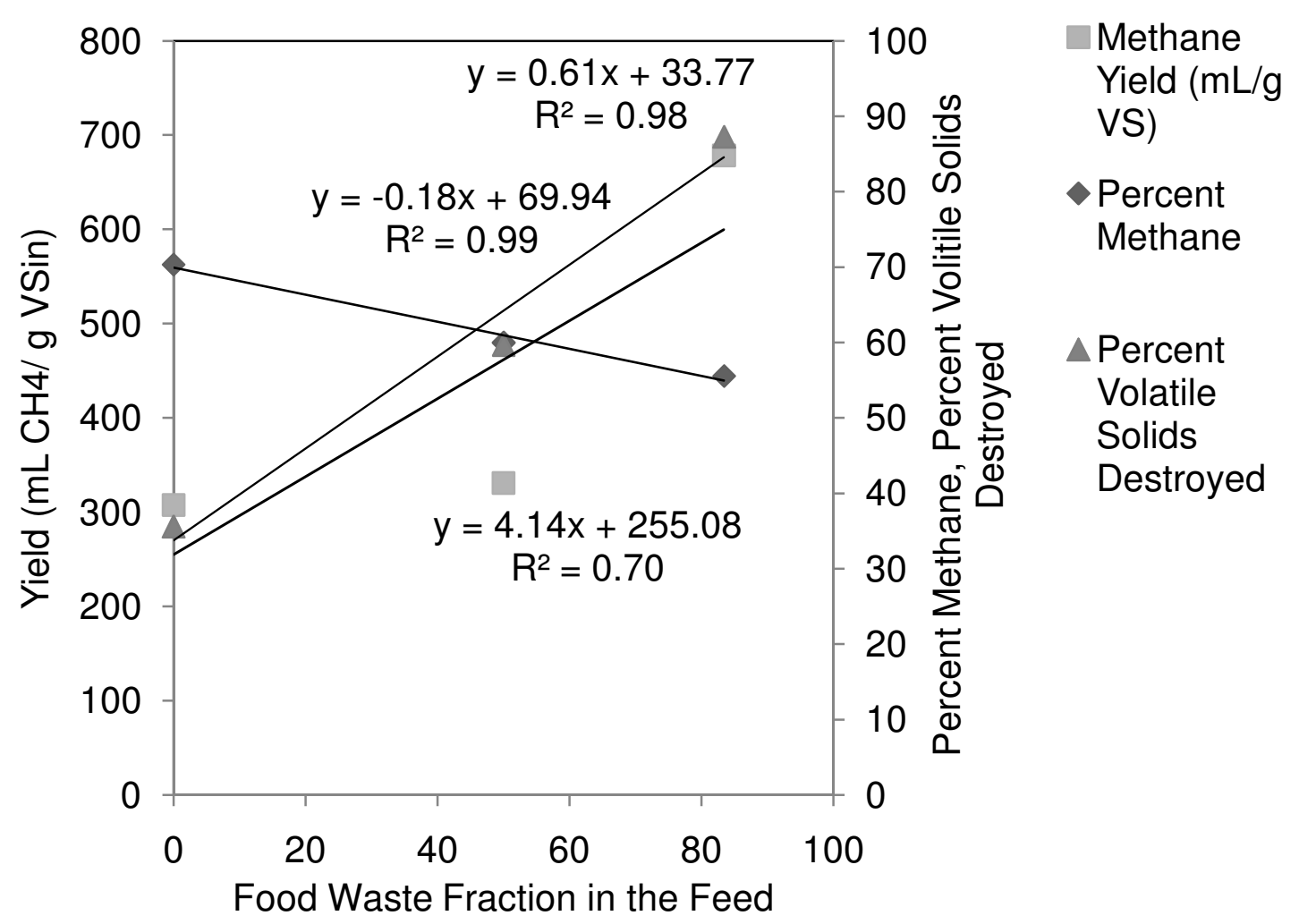

Figure 15: Effect of food waste in the feed on yield, percent methane, and volatile solids destruction. This graph shows the average value for the three different percentages of food waste in the feed.

\section{SLUDGE CONTENT}

The sludge content in the feed is the inverse of algae and food waste content and, thus, sludge percentage is not considered separately.

\section{ORGANIC LOADING RATE}

Over the two experiments, four different organic loading rates were used, ranging from 1$5.5 \mathrm{~g} \mathrm{VS} / \mathrm{L}-\mathrm{d}$ (Table 3). The lowest loading rate was $1 \mathrm{~g} \mathrm{VS} / \mathrm{L}$-day for Digester 2.10 that was fed $80 \%$ algae, and $20 \%$ sludge at a 40 day residence time. The yield for this digester was $0.27 \mathrm{~L} \mathrm{CH}_{4} / \mathrm{g} \mathrm{VS}_{\text {in }}$. Eleven digesters were fed at a rate of $2 \mathrm{~g} \mathrm{VS} / \mathrm{L}$-day and showed yields ranging from $0.24-0.68 \mathrm{~L} \mathrm{CH}_{4} / \mathrm{g} \mathrm{VS}_{\text {in }}$. Five digesters were fed at a rate of 
$4 \mathrm{~g} \mathrm{VS} / \mathrm{L}$-day and showed yields ranging from $0.21-0.34 \mathrm{~L} \mathrm{CH}_{4} / \mathrm{g} \mathrm{VS}_{\mathrm{in}}$. Finally, Digester 2.8 was loaded at rate of $5.5 \mathrm{~g} \mathrm{VS} / \mathrm{L}$-day and showed yield of $0.25 \mathrm{~L} \mathrm{CH}_{4} / \mathrm{g}$ $\mathrm{VS}_{\text {in }}$

For digesters fed $100 \%$ algae and digesters fed $80 \%$ algae and $20 \%$ sludge, increasing the organic loading rate from 2 to $4 \mathrm{~g}$ VS/L-day did not cause a discernable difference in methane yield (Figure 16). The digesters fed $40 \%$ algae, $50 \%$ food waste, and $10 \%$ sludge showed a decrease of $0.06 \mathrm{~L} \mathrm{CH}_{4} / \mathrm{g} \mathrm{VS}_{\text {in }}$ as the loading rate increased from 2 to 4 $\mathrm{g}$ VS/L-day. These data showed that increasing the organic loading rate from 2 to $4 \mathrm{~g}$ VS/L-day did not provide any additional biogas production and may some cases caused a decrease in biogas production. A similar effect was observed for volatile solids destruction and the percent methane in the biogas. While digestion at loading rates up to $4 \mathrm{~g}$ VS/L-day proved highly stable, digestion at $5.5 \mathrm{~g}$ VS/L-day proved unstable. 


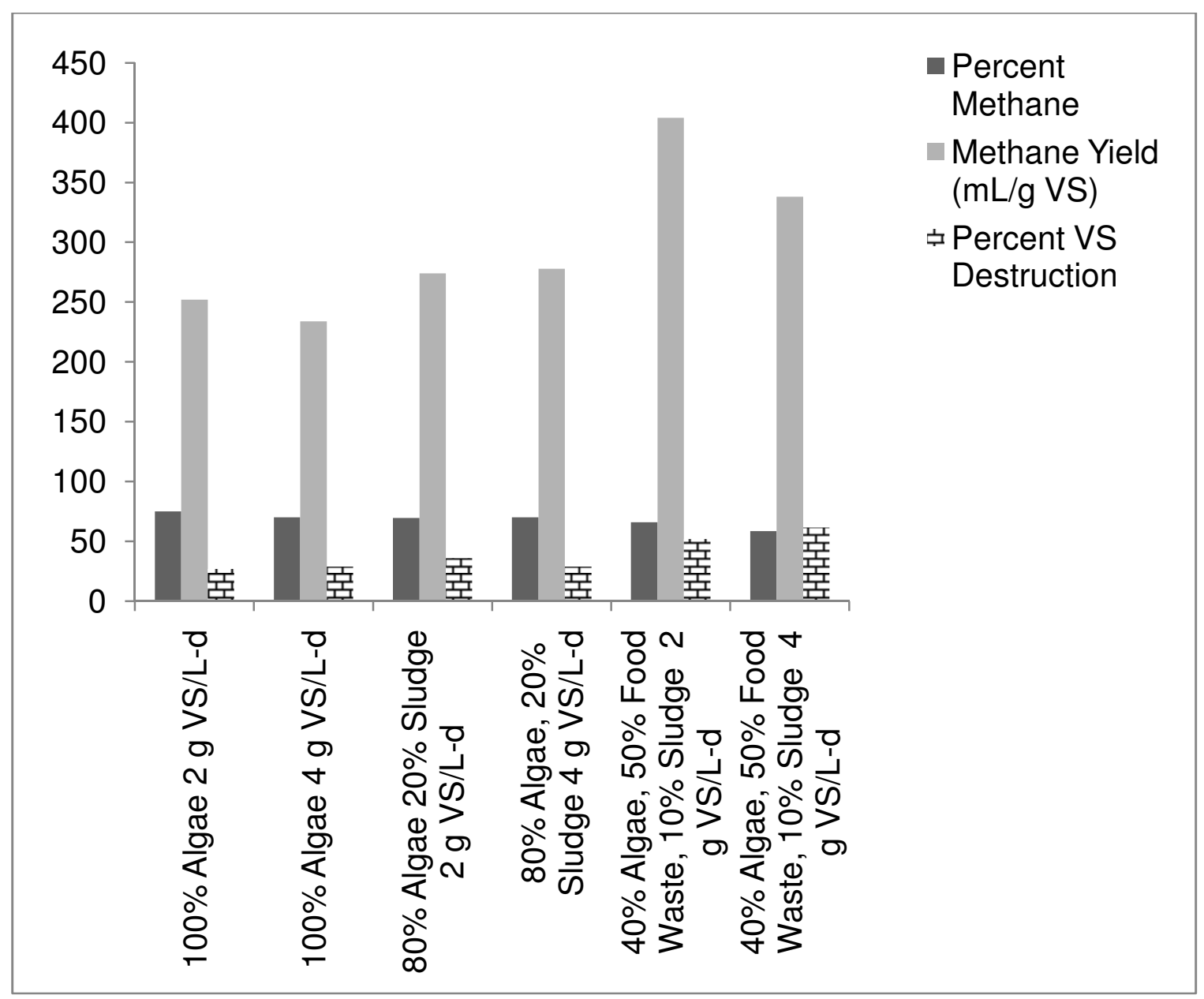

Figure 16: The effect of organic loading on methane yield, volatile solids destruction, and percent methane in the biogas for pairs of digesters with the same residence time and feed composition.

\section{HYDRAULIC RESIDENCE TIME}

Only one digester was tested with a hydraulic residence time of 40 days, while all others were operated at 20 days. For comparison of the effect of hydraulic residence time on methane yield, volatile solids destruction, and biogas quality digesters with the same feed of $80 \%$ algae and $20 \%$ sludge were chosen. The two digesters were operated at an organic loading rate of $2 \mathrm{~g} \mathrm{VS/L-day} \mathrm{and} \mathrm{a} \mathrm{20-day} \mathrm{residence} \mathrm{time,} \mathrm{while} \mathrm{the} \mathrm{final} \mathrm{digester}$ 
was operated at a loading rate of $1 \mathrm{~g} \mathrm{VS/L-day} \mathrm{and} \mathrm{a} \mathrm{40-day} \mathrm{residence} \mathrm{time.} \mathrm{Despite} \mathrm{a}$ lower loading rate, the digester operating at 40-day residence time showed remarkably similar methane yields, operational parameters, and solids destruction compared to the digesters operating at a higher residence time and higher loading rate (Figure 17).

Alkalinity was the only operational parameter that was higher for the longer residence time of 40 days.

Although the effect of increasing organic loading rate on methane yield was difficult to discern using the single variable of organic loading rate, low organic loading rates could be expected to eventually decrease methane yield due to an unavailability of digestible substrate. More research is needed to determine if the yield results of this experiment are largely due to the low loading rate or the longer residence time or some combination of the two factors. However, due to the recalcitrant nature of algae cells, longer residence times will likely result in higher methane yields at the same loading rates and more stable digesters. 


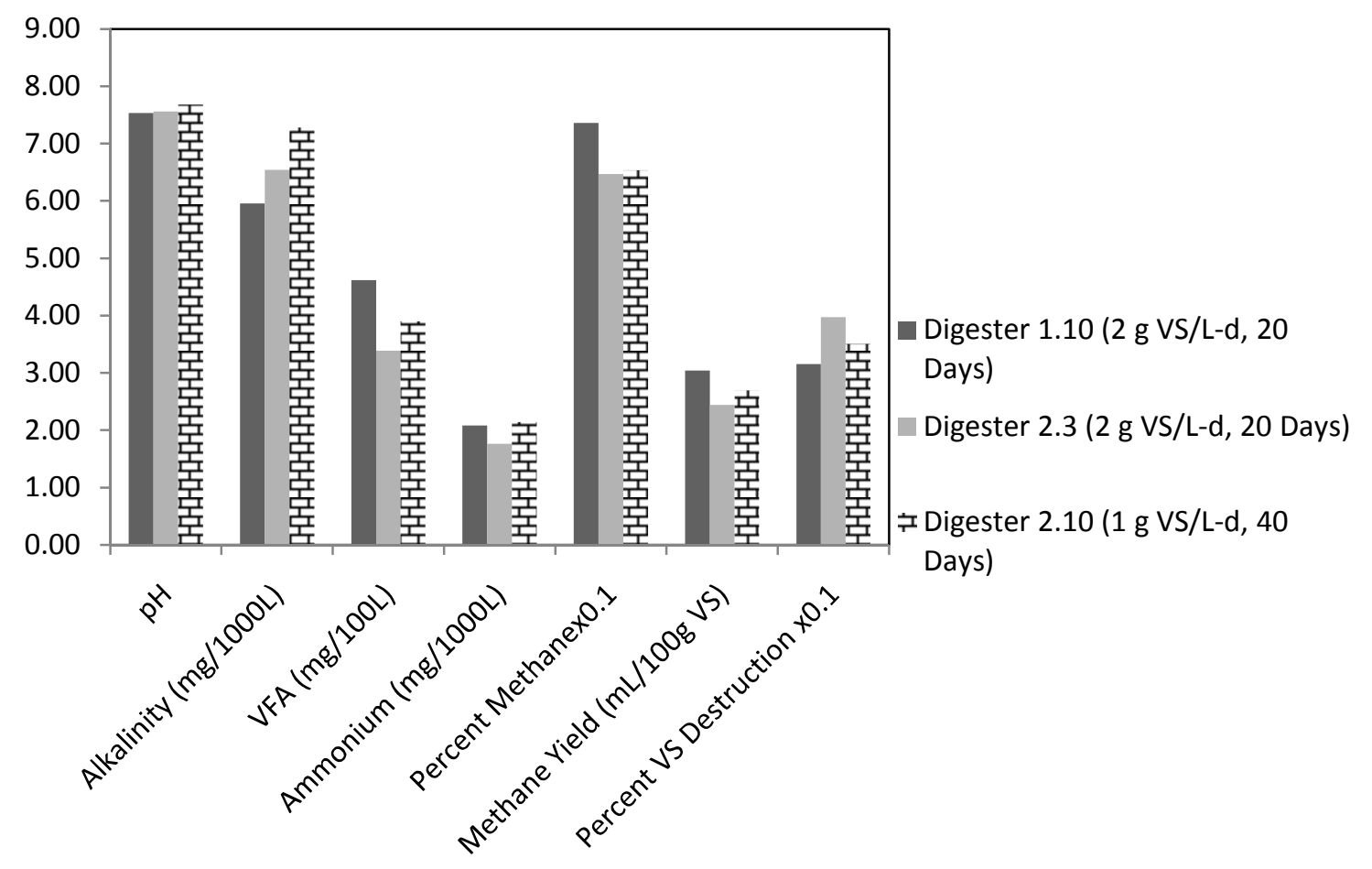

Figure 17: Comparison of three digesters fed $80 \%$ algae and $20 \%$ sludge. Digester 1.10 and 2.3 were fed at a rate of $2 \mathrm{~g} \mathrm{VS/L-day} \mathrm{and} \mathrm{a} \mathrm{20-day} \mathrm{residence} \mathrm{time,} \mathrm{and} \mathrm{Digester} 2.10$ was fed at a rate of $1 \mathrm{~g} \mathrm{VS/L-d} \mathrm{and} \mathrm{a} \mathrm{40-day} \mathrm{residence} \mathrm{time.}$ 
Table 3: Average steady state values calculated by determining the intersection of steady state periods for gas production, volatile solids destruction (VSD), $\mathrm{pH}$, and alkalinity, ammonium, and volatile fatty acids concentrations. The line down the middle of the graph separates independent variables on the left from dependent variables on the right.

\begin{tabular}{|c|c|c|c|c|c|c|c|c|c|c|c|c|}
\hline $\begin{array}{l}\text { Digester } \\
\text { Number }\end{array}$ & $\begin{array}{c}\text { Residence } \\
\text { Time } \\
\text { (days) }\end{array}$ & $\begin{array}{c}\text { OLR } \\
(\mathrm{g} \\
\mathrm{VS} / \mathrm{L} \\
-\mathrm{d})\end{array}$ & $\begin{array}{c}\text { Algae } \\
\text { Content } \\
(\%)\end{array}$ & $\begin{array}{c}\text { Food } \\
\text { Waste } \\
\text { Content } \\
(\%)\end{array}$ & $\begin{array}{c}\text { Sludge } \\
\text { Content } \\
(\%)\end{array}$ & $\overline{\mathrm{pH}}$ & $\begin{array}{c}\text { Alkalinity } \\
\text { (mg } \\
\mathrm{CaCO}_{3} \\
/ \mathrm{L})\end{array}$ & $\begin{array}{c}\text { VFA } \\
(\mathrm{mg} \\
\text { acetic } \\
\text { acid } \\
/ \mathrm{L})\end{array}$ & $\begin{array}{c}\text { Total } \\
\text { Ammonia } \\
(\mathrm{mg} \mathrm{N} / \mathrm{L})\end{array}$ & $\begin{array}{c}\text { Percent } \\
\mathrm{CH}_{4} \\
(\%)\end{array}$ & $\begin{array}{c}\text { Methane } \\
\text { Yield } \\
(\mathrm{L} / \mathrm{g} \text { VS })\end{array}$ & $\begin{array}{c}\text { VSD } \\
(\%)\end{array}$ \\
\hline 1.1 & 20 & 2 & 100 & 0 & 0 & 7.52 & 6260 & 828 & 1680 & 74 & 0.25 & 27 \\
\hline 1.2 & 20 & 2 & 100 & 0 & 0 & 7.52 & 6280 & 748 & 1740 & 76 & 0.25 & 27 \\
\hline 1.7 & 20 & 2 & 40 & 0 & 60 & 7.43 & 5920 & 240 & 1730 & 70 & 0.38 & 41 \\
\hline 1.8 & 20 & 2 & 60 & 0 & 40 & 7.50 & 5830 & 60 & 1660 & 73 & 0.36 & 37 \\
\hline 1.9 & 20 & 2 & 60 & 0 & 40 & 7.48 & 5930 & 210 & 1810 & 72 & 0.36 & 33 \\
\hline 1.10 & 20 & 2 & 80 & 0 & 20 & 7.53 & 5960 & 462 & 2090 & 74 & 0.30 & 32 \\
\hline 2.1 & 20 & 4 & 100 & 0 & 0 & 7.61 & 11200 & 4600 & 3360 & 69 & 0.21 & 28 \\
\hline 2.6 & 20 & 4 & 40 & 50 & 10 & 7.70 & 8540 & 2810 & 2470 & 58 & 0.34 & 63 \\
\hline 2.7 & 20 & 4 & 40 & 50 & 10 & 7.70 & 8620 & 3470 & 2580 & 59 & 0.34 & 60 \\
\hline 2.8 & 20 & 5.5 & 40 & 50 & 10 & 7.52 & 10300 & 10900 & 3450 & 57 & 0.25 & 63 \\
\hline 2.9 & 20 & 2 & 0 & 83.4 & 16.6 & 6.78 & 5100 & 5150 & 1650 & 56 & 0.68 & 87 \\
\hline 2.10 & 40 & 1 & 80 & 0 & 20 & 7.68 & 7280 & 390 & 2140 & 65 & 0.27 & 35 \\
\hline
\end{tabular}




\section{EXTENDED MODEL}

Two types of descriptive models were developed: the extended models which incorporated more parameters and the compact models which used only the significant parameters with a p-value less than 0.05 . The linear multivariate least squares method was used to create these models using data identified in steady state periods. The independent variables included the hydraulic residence time, the organic loading rate, and the algae and food waste content in the feed. Sludge was a repetitive variable and shows the inverse effect of algae content or food waste content in the feed. The independent variables included methane yield, percent volatile solids destruction, and percent methane in the biogas, total ammonia nitrogen, alkalinity and volatile fatty acids concentrations. Before the data were entered into the model, each independent and dependent variable was plotted against each other to test for a linear relationship between the variables and, when possible, the values were tested to determine if they were part of a normal distribution. Based on testing schedules, the availability of digester effluent, and the volume of digester effluent needed for each test, the number of values used to determine the model average values varied by constituent (Table 4).

The extended model was used to determine the strength of the relationship between the respective $\mathrm{x}$ and $\mathrm{y}$ variables. $\mathrm{P}$-values less than 0.05 indicate that there is a $5 \%$ chance or less that the $\mathrm{x}$-variable has no effect on the $\mathrm{y}$-variable; therefore, for these models $\mathrm{x}$ coefficients with p-values less than 0.05 were defined as significant in determining the $y$ value with a $95 \%$ confidence. Because some of the parameters in the extended model were not found to be statistically significant, compact models were also developed by 
eliminating parameters with $\mathrm{p}$-values greater than 0.05 . The less significant variables and residence time variable were then eliminated in the compact models. Residence time was eliminated because only two levels were tested, and only one digester was tested at the higher 40-day residence time. The data discussed in the following modeling sections use the average values from the steady state periods. 
Table 4: Model steady state periods and the number of values averaged for each value used in the model.

\begin{tabular}{|c|c|c|c|c|c|c|c|c|}
\hline $\begin{array}{l}\text { Digester } \\
\text { Number }\end{array}$ & $\begin{array}{l}\text { Steady state } \\
\text { period } \\
\text { (days) }\end{array}$ & $\begin{array}{l}\mathrm{pH} \\
\text { (n) }\end{array}$ & $\begin{array}{l}\text { Alkalinity } \\
\text { (n) }\end{array}$ & $\begin{array}{c}\text { VFA } \\
\text { (n) }\end{array}$ & $\begin{array}{l}\text { Ammonium } \\
\text { (n) }\end{array}$ & $\begin{array}{c}\% \\
\text { Methane } \\
\text { (n) }\end{array}$ & $\begin{array}{l}\mathrm{CH}_{4} \\
\text { Yield } \\
(\mathrm{n})\end{array}$ & $\begin{array}{c}\% \mathrm{VS} \\
\text { Destruction } \\
\text { (n) }\end{array}$ \\
\hline 1.1 & $29-50$ & 20 & 6 & 3 & 1 & 4 & 20 & 4 \\
\hline 1.2 & $29-50$ & 20 & 6 & 3 & 1 & 4 & 21 & 4 \\
\hline 1.5 & $29-50$ & 20 & 6 & 3 & 1 & 4 & 19 & 4 \\
\hline 1.6 & $29-43$ & 14 & 5 & 2 & 1 & 3 & 14 & 3 \\
\hline 1.7 & $22-43$ & 21 & 7 & 2 & 1 & 4 & 19 & 4 \\
\hline 1.8 & $29-50$ & 20 & 6 & 3 & 1 & 4 & 21 & 4 \\
\hline 1.9 & $29-50$ & 20 & 6 & 2 & 1 & 4 & 20 & 4 \\
\hline 1.10 & $36-50$ & 13 & 4 & 2 & 1 & 3 & 14 & 3 \\
\hline 2.1 & $62-90$ & 22 & 14 & 4 & 5 & 5 & 28 & 5 \\
\hline 2.2 & $62-83$ & 18 & 11 & 3 & 4 & 4 & 21 & 4 \\
\hline 2.3 & $27-55$ & 19 & 9 & 4 & 4 & 5 & 28 & 5 \\
\hline 2.4 & $62-83$ & 18 & 11 & 3 & 4 & 4 & 21 & 4 \\
\hline 2.5 & $34-62$ & 22 & 9 & 2 & 4 & 5 & 28 & 5 \\
\hline 2.6 & $34-55$ & 15 & 6 & 3 & 3 & 4 & 21 & 4 \\
\hline 2.7 & $34-55$ & 15 & 6 & 3 & 3 & 4 & 21 & 4 \\
\hline 2.8 & $41-55$ & 11 & 4 & 2 & 2 & 3 & 12 & 3 \\
\hline 2.9 & $69-90$ & 16 & 11 & 3 & 3 & 4 & 21 & 4 \\
\hline 2.10 & $34-55$ & 15 & 6 & 2 & 3 & 4 & 21 & 4 \\
\hline
\end{tabular}




\section{ALKALINITY MODEL}

Alkalinity concentrations from $2000-4000 \mathrm{mg} \mathrm{CaCO}_{3} / \mathrm{L}$ are needed to buffer volatile fatty acids and carbon dioxide and maintain the $\mathrm{pH}$ near neutral (Metcalf and Eddy 2003). The steady state periods for all the digesters exceeded this requirement with a low concentration of 5,100 mg CaCO $3 / \mathrm{L}$ and a high concentration of $11,200 \mathrm{mg} \mathrm{CaCO} / \mathrm{L}$. The extended model shows that alkalinity was higher when the residence time, organic loading rate and algae content in the feed were higher, and alkalinity was lower when the food waste in the feed was higher (Equation 3). Ultimately, at some ceiling organic loading rate, the alkalinity would be expected to drop off sharply as the digester became overloaded, but this was not observed for the steady state periods. The most significant variables for predicting alkalinity as measured by p-values, were organic loading rate (OLR g VS/L-d), residence time (days), and algae content (percent algae) in the digester feed (Table 5).

$$
\begin{aligned}
\text { Alkalinity }(\mathrm{mg} / \mathrm{L})= & -383+124 \text { Residence Time }+1680 \text { OLR }+12.6 \text { Algae } \\
& -10.9 \text { Food Waste }
\end{aligned}
$$


Table 5: Statistical analysis of the influence of residence time, organic loading rate, and algae and food waste content in the feed on alkalinity concentrations in the digester effluents.

\begin{tabular}{lcccc}
\hline \hline Predictor & Coefficient & Standard Error & $\mathrm{t}$ & $\mathrm{p}$ \\
\hline & & & & \\
Constant & -383.4 & 914.5 & -0.42 & 0.682 \\
Residence Time & 124.23 & 34.40 & 3.61 & 0.003 \\
OLR & 1680.1 & 147.9 & 11.36 & 0.000 \\
Algae & 12.634 & 5.843 & 2.16 & 0.050 \\
Food Waste & 10.950 & 7.411 & -1.48 & 0.163 \\
& & & & \\
\hline R-Squared & $93.1 \%$ & & \\
\hline
\end{tabular}

Standard residuals were analyzed to determine if digesters with large residuals were related in some way. If consistencies existed between the digesters, this would indicate the independent variable ranges where the model was less reliable in predicting the dependent variable. For the alkalinity model, Digesters 2.1, 2. 4, and 2.8 showed standard residuals above 1.00 in the alkalinity regression analysis (Figure 18). Each of these digesters with a large residual was operated at or above the loading rate of $4 \mathrm{~g}$ VS/L-d and had an algae content above 40\%. Digester 2.8, which was loaded at $5.5 \mathrm{~g}$ VS/L-d, had a very high alkalinity but was experiencing toxicity due to a high volatile fatty acid concentration. Digester 2.1 had a large standard residual, but its duplicate Digester 2.2 had a low standard residual. These digesters were loaded at $4 \mathrm{~g}$ VS/L-d with 100\% algae feed. Comparing Digester 2.4 to Digesters 2.6 and 2.7, all digesters were loaded at $4 \mathrm{~g} \mathrm{VS} / \mathrm{L}-\mathrm{d}$, but the feed in Digester 2.4 contained $80 \%$ algae and $20 \%$ sludge while the feed in Digesters 2.6 and 2.7 contained 50\% food waste, $40 \%$ algae and $10 \%$ sludge and had much lower standard residuals. Increasing organic loading rate and algae percentage tended to increase the standard residuals for the regression analysis; therefore, 
when using the compact model results from inputs with higher organic loading rates and algae content, values should be given less confidence because uncertainty is greater for these situations.

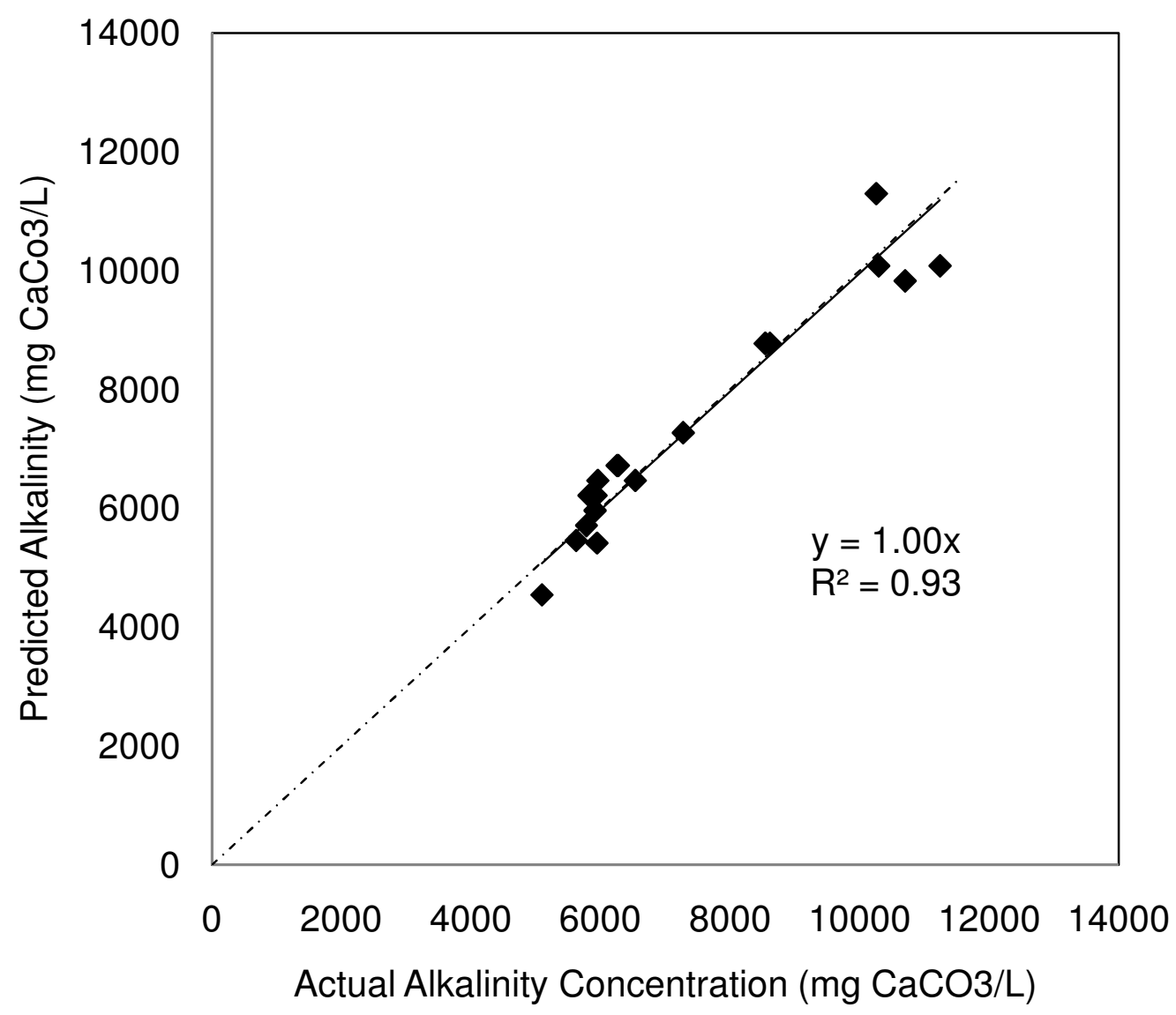

Figure 18: Plot showing the predicted alkalinity concentration as determined from the extended model equation compared to the actual measured average alkalinity concentration for the steady state period. The dashed line indicates the one to one line while the solid line indicates the line of best fit for the data points. 


\section{VOLATILE FATTY ACIDS MODEL}

An increase in volatile fatty acid concentration indicates that the methanogens are being overloaded, or some other environmental factor is limiting their ability to convert volatile fatty acids to methane. A build-up can lead to a drop in $\mathrm{pH}$ and a culture crash; therefore, volatile fatty acids are an important indicator of process stability. Volatile fatty acid concentrations used in the regression ranged from 56-10,900 $\mathrm{mg}$ acetic acid/L. The model shows that volatile fatty acids were higher in digesters with higher residence times, organic loadings, and algae and food waste content in the feed (Equation 4). The most significant variables for predicting volatile fatty acids, as indicated by p-values, are organic loading rate (OLR g VS/L-d) and food waste (\%) in the feed (Table 6).

$$
\begin{aligned}
& \text { VFA }(\mathrm{mg} / \mathrm{L})=-5436+97.1 \text { Residence Time + 1762 OLR + 2.2 Algae } \\
& \text { +36.5 Food Waste } \quad \text { Equation } 4
\end{aligned}
$$

Table 6: Statistical analysis of the influence of residence time, organic loading rate, and algae and food waste content in the feed on volatile fatty acid concentrations in the digester effluents.

\begin{tabular}{lcccc}
\hline Predictor & Coefficient & Standard Error & $\mathrm{t}$ & $\mathrm{p}$ \\
\hline & & & & \\
Constant & -5436 & 2235 & -2.43 & 0.030 \\
Residence Time & 97.11 & 84.05 & 1.16 & 0.269 \\
OLR & 1762.3 & 361.5 & 4.87 & 0.000 \\
Algae & 2.24 & 14.28 & 0.16 & 0.878 \\
Food Waste & 36.52 & 18.11 & 2.02 & 0.065 \\
& & & & \\
\hline R-Squared & $78.4 \%$ & & & \\
\hline
\end{tabular}

The standard residuals for Digesters 2.5, 2.6, 2.7, 2.8 and 2.9, or all the food waste digesters were above 1.00 in the alkalinity regression analysis (Figure 19). Digesters 2.8 and 2.9 had measured volatile fatty acid concentrations greater than the value predicted 
by the equation. Digester 2.8 had the highest organic loading of $5.5 \mathrm{~g} \mathrm{VS} / \mathrm{L}-\mathrm{d}$, which caused volatile fatty acids to accumulate and the digester to experience a culture crash. This extreme value of $10,900 \mathrm{mg}$ acetic acid/L caused the line of best fit to skew downwards. Digester 2.9 also experienced higher than expected volatile fatty acid concentrations based on its loading of $2 \mathrm{~g} \mathrm{VS} / \mathrm{L}-\mathrm{d}$, but it was the only digester to contain carbon-rich food waste and sludge with no algae. Due to the high carbon content of the feed, this relatively high volatile fatty acid concentration of 5,200 $\mathrm{mg}$ acetic acid/L may be typical of food waste and sludge digester. The compact model equation should not be used for digesters that contain food waste alone because insufficient data exists to predict yields. Overall, digesters with higher organic loading rates and containing food waste showed a higher degree of variability. 


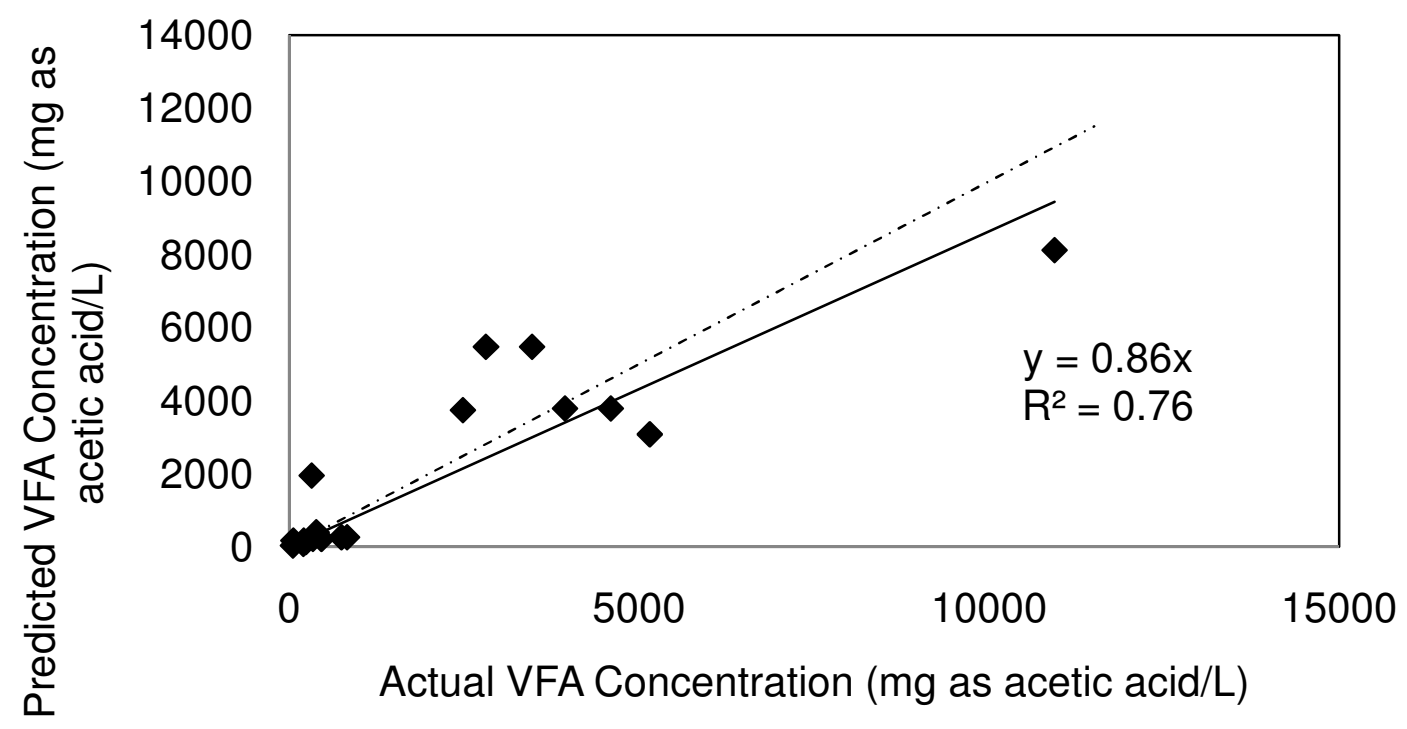

Figure 19: Plot showing the predicted volatile fatty acid concentration as determined from the extended model equation compared to the actual measured average volatile fatty acid concentration for the steady state period. The dashed line indicates the one to one line while the solid line indicates the line of best fit for the data points.

\section{AMMONIUM NITROGEN MODEL}

The presence of ammonia in solution can significantly inhibit anaerobic bacteria, and in previous algae digestion studies has been found to be a primary cause of poor digestion. In this experiment total ammonia nitrogen concentrations ranged from 1230-3450 mg N/L. The model shows that ammonia nitrogen concentrations were higher in digesters with longer residence times, higher organic loading rates, and algae in the feed and were lower with higher food waste content in the feed (Equation 5). The most significant variables for predicting ammonia nitrogen concentration, as measured by p-values, are organic loading rate (OLR g VS/L-d), residence time (days), and algae content (\%) in the feed (Table 7). 
Ammonia (mg N/L) = - 616 + 45.2 Residence Time + 597 OLR + 4.41Algae-

Table 7: Statistical analysis of the influence of residence time, organic loading rate, and algae and food waste content in the feed on ammonia nitrogen concentrations in the digester effluents.

\begin{tabular}{lcccc}
\hline Predictor & Coefficient & Standard Error & $\mathrm{t}$ & $\mathrm{p}$ \\
\hline & & & & \\
Constant & -615.7 & 340.0 & -1.81 & 0.093 \\
Residence Time & 45.20 & 12.79 & 3.53 & 0.004 \\
OLR & 597.06 & 55.00 & 10.86 & 0.000 \\
Algae & 4.412 & 2.172 & 2.03 & 0.063 \\
Food Waste & -3.297 & 2.755 & -1.20 & 0.253 \\
& & & & \\
\hline R-Squared & $92.5 \%$ & & & \\
\hline
\end{tabular}

The standard residuals for Digesters 1.1, 1.10, 2.1, 2.2, 2.5, 2.6 and 2.9 were above 1.00 in the ammonia nitrogen regression analysis (Figure 20). These larger standard residuals were evenly distributed above and below the line of best fit, from low to high ammonia nitrogen concentrations, and have no readily apparent relationship to any specific variable. Therefore, the larger standard residuals are most likely attributable to natural variation. 


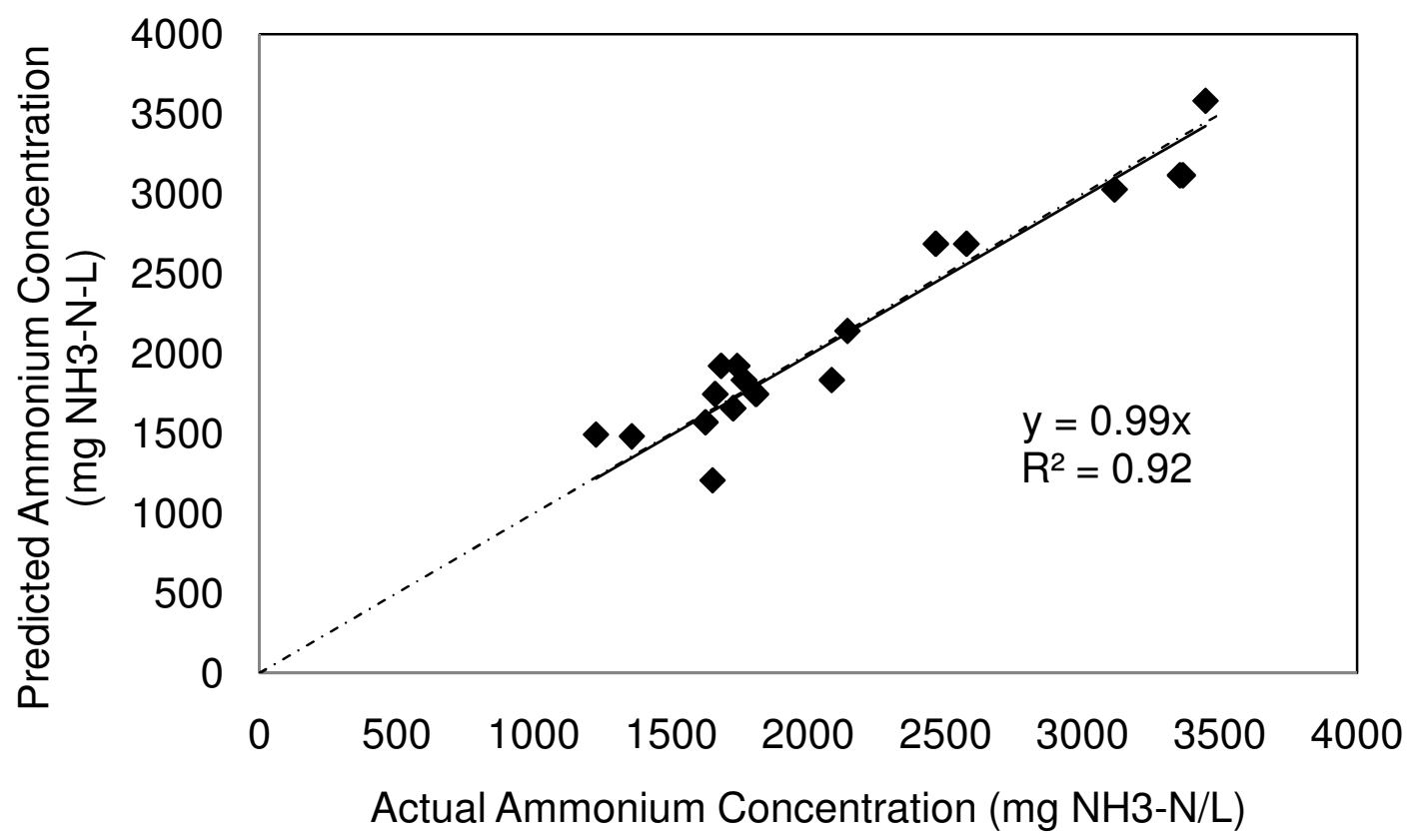

Figure 20: Plot showing the predicted ammonia nitrogen concentration as determined from the extended model equation compared to the actual measured average ammonia nitrogen concentration for the steady state period. The dashed line indicates the one to one line while the solid line indicates the line of best fit for the data points.

\section{BIOGAS QUALITY MODEL}

For this experiment, methane concentrations ranged from 56-76\%. For algae sludge digesters, methane percentage ranged from $65-76 \%$ with the highest methane concentrations observed in digesters with $100 \%$ algae feed, a 20-day residence time, and a $2 \mathrm{~g} \mathrm{VS/L-d} \mathrm{organic} \mathrm{loading} \mathrm{rate.} \mathrm{Greater} \mathrm{methane} \mathrm{content} \mathrm{was} \mathrm{observed} \mathrm{in} \mathrm{digesters}$ given feed with higher algae contents, while higher values of all other variables led to lower methane content (Equation 6). This result shows that, while algae may not degrade to the extent of other digester feeds, the fraction that does degrade creates high quality biogas. The most significant variables for predicting percent methane as measured by $\mathrm{p}$ - 
values are residence time (days), organic loading rate (OLR g VS/L-d), and algae and food waste content $(\%)$ in the feed (Table 8$)$.

$$
\begin{aligned}
\text { Percent Methane }= & 80.4-0.456 \text { Residence Time }-1.94 \text { OLR }+0.0639 \text { Algae- } \\
& 0.133 \text { Food Waste }
\end{aligned}
$$

Table 8: Statistical analysis of the influence of residence time, organic loading rate, and algae and food waste content in the feed on the methane content in the biogas.

\begin{tabular}{lcccc}
\hline \hline Predictor & Coefficient & Standard Error & $\mathrm{t}$ & $\mathrm{p}$ \\
\hline Constant & 80.394 & 3.957 & 20.32 & 0.000 \\
Residence Time & -0.4564 & 0.1488 & -3.07 & 0.009 \\
OLR & -1.9369 & 0.6401 & -3.03 & 0.010 \\
Algae & 0.06394 & 0.02528 & 2.53 & 0.025 \\
Food Waste & -0.13310 & 0.03207 & .4015 & 0.001 \\
& & & & \\
\hline R-Squared & $86.4 \%$ & & & \\
\hline
\end{tabular}

The standard residuals for Digesters 2.3 and 2.5 were above 1.00 in the biogas quality regression analysis (Figure 21). Digester 2.3 and Digester 1.10 were duplicates loaded at $2 \mathrm{~g} \mathrm{VS} / \mathrm{L}-\mathrm{d}$ with a 20-day residence time and a feed consisting of $80 \%$ algae and $20 \%$ sludge, but while Digester 2.3 exhibited a large standard residual Digester 1.10 did not. Between duplicate Digesters 2.3 and 1.10 there was a nearly $10 \%$ difference in biogas quality. Digester 2.3 also did not fit into the overall pattern of higher biogas quality with higher algae content in the feed. The other digester with the large residual, Digester 2.5 exhibited a higher than expected biogas quality. Overall, there is no readily attributable variable or reason for the variation of these two points around the point of best fit and in general the standard residuals are evenly distributed above and below the line of best fit, from low to high biogas quality, and have no readily apparent relationship to any specific 
variable. Therefore, the larger standard residuals may have been caused by natural variation.

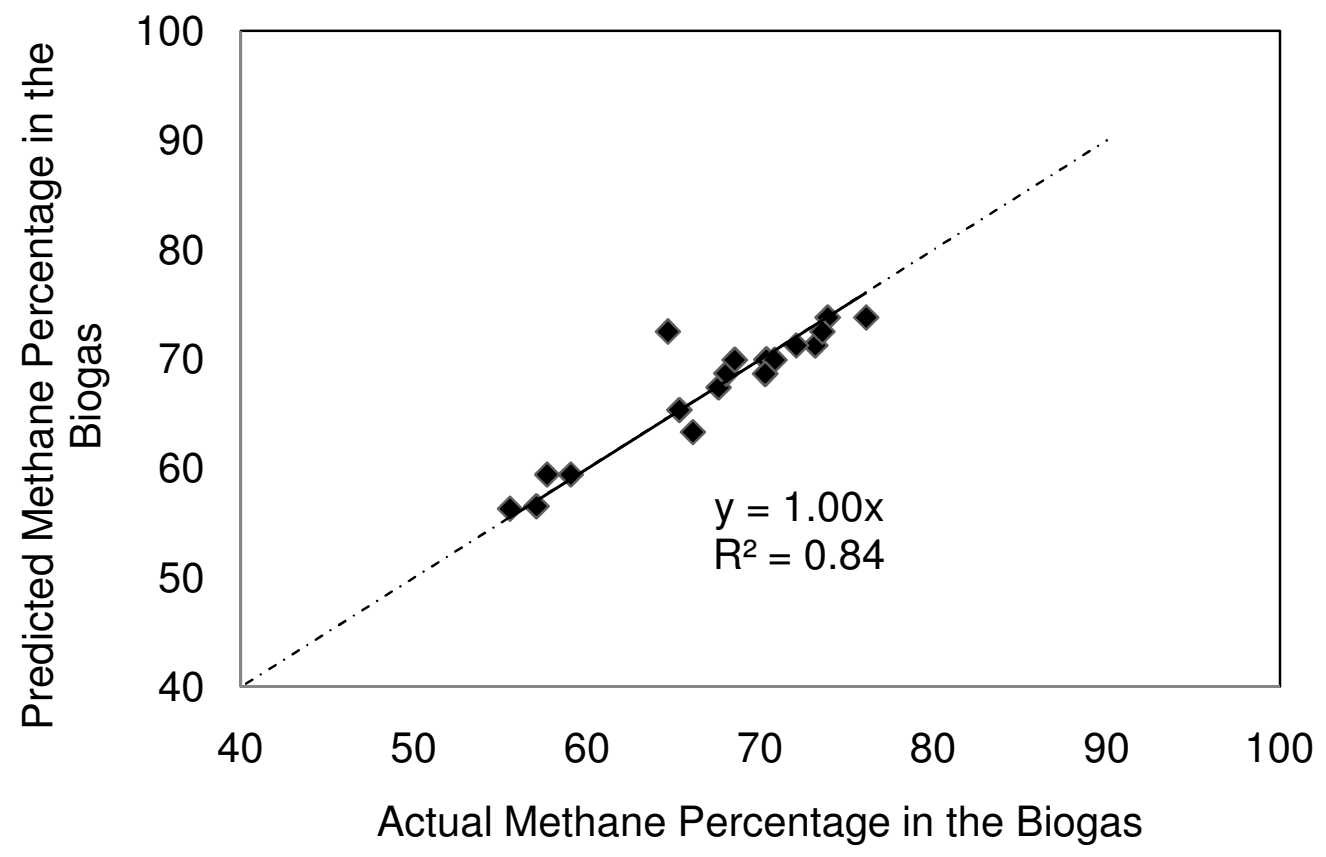

Figure 21: Plot showing the predicted biogas quality as determined from the extended model equation compared to the actual measured average biogas quality for the steady state period. The dashed line indicates the one to one line while the solid line indicates the line of best fit for the data points. 


\section{YIELD MODEL}

For this experiment, the total methane yield ranged from $0.21-0.68 \mathrm{~L} \mathrm{CH}_{4} / \mathrm{g} \mathrm{VS}_{\text {in }}$ with the highest yield digester containing $83.4 \%$ food waste and $16.6 \%$ sludge at a 20 -day hydraulic residence time and a $2 \mathrm{~g} \mathrm{VS} / \mathrm{L}$-day organic loading rate. The digester with the lowest yield digester contained $100 \%$ algae feed at a 20 -day hydraulic residence time and a $4 \mathrm{~g} \mathrm{VS/L-day} \mathrm{organic} \mathrm{loading} \mathrm{rate.} \mathrm{For} \mathrm{digesters} \mathrm{containing} \mathrm{algae} \mathrm{and/or} \mathrm{sludge,} \mathrm{the}$ yield ranged from $0.21-0.40 \mathrm{~L} \mathrm{CH}_{4} / \mathrm{g} \mathrm{VS}$ in. The regression shows that longer residence times and higher food waste content in the feed resulted in a higher the methane yield, while higher organic loading rates and algae content in the feed resulted in a lower methane yield (Equation 7). The most significant variables for predicting yield, as measured by p-values, were organic loading rate (OLR g VS/L-d) and algae and food waste content (\%) in the feed (Table 9).

Methane Yield $(\mathrm{mL} / \mathrm{g}$ VS) $=613-4.25$ Residence Time -45.3 OLR

$$
\text { - 1.60 Algae + 1.69 Food Waste Equation } 7
$$

Table 9: Statistical analysis of the influence of residence time, organic loading rate, and algae and food waste content in the feed on the methane yield.

\begin{tabular}{lcccc}
\hline \hline Predictor & Coefficient & Standard Error & $\mathrm{t}$ & $\mathrm{p}$ \\
\hline & & & & \\
Constant & 612.85 & 76.00 & 8.06 & 0.000 \\
Residence Time & -4.251 & 2.858 & -1.49 & 0.161 \\
OLR & -45.25 & 12.29 & -3.68 & 0.003 \\
Algae & -1.6040 & 0.4856 & -3.30 & 0.006 \\
Food Waste & 1.6891 & 0.6159 & 2.74 & 0.017 \\
& & & & \\
\hline R-Squared & $83.1 \%$ & & \\
\hline
\end{tabular}


The standard residuals for Digesters 2.2, 2.3, 2.4, 2.5, 2.8, and 2.9 were above 1.00 in the methane yield regression analysis (Figure 22). Digester 2.8 showed a lower than expected yield because it had a high loading rate of $5.5 \mathrm{~g}$ VS/L-d that caused fatty acid toxicity and depressed biogas production. Digesters 2.3 and 2.5 also had lower than expected yield values based on the model. Digesters 2.2, 2.4 and 2.9, had higher than expected yield values based on the model. Digester 2.9 had the highest concentration of food waste in the feed and the highest yield of the whole experiment. It was also the only digester that contained only food waste and sludge, with no algae. The compact model equation should not be used for digesters that contain food waste alone because insufficient data have been collected to predict yields. More variability in yield appeared in digesters with high organic loading rates with a high content of algae or food waste in the feed. 


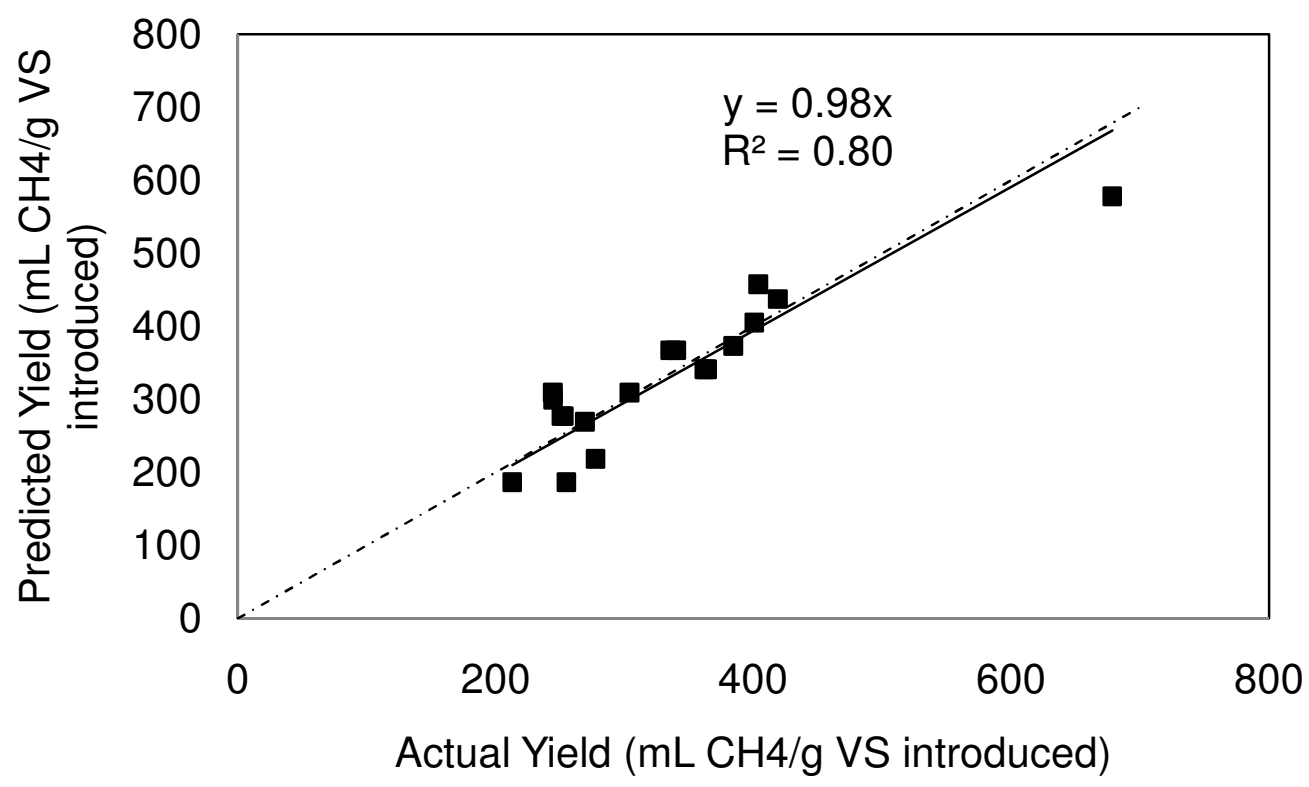

Figure 22: Plot showing the predicted yield as determined from the extended model equation compared to the actual measured average yield for the steady state period. The dashed line indicates the one to one line while the solid line indicates the line of best fit for the data points.

\section{VOLATILE SOLIDS DESTRUCTION MODEL}

For this experiment, the percent volatile solids destruction ranged from $27-87 \%$. The model shows that longer residence times, and higher organic loading rates, and food waste content in the feed corresponds to higher volatile solids destruction while higher algae content in the feed corresponds to lower volatile solids destruction (Equation 8). The most significant variables for predicting volatile solids destruction, as measured by p-values, are residence time (days), algae and food waste content $(\%)$ in the digester feed (Table 10).

Percent VS Destruction $=48.9+0.188$ Residence Time +0.587 OLR

$$
\text { - 0.275Algae + 0.349 Food Waste Equation } 8
$$


Table 10: Statistical analysis of the influence of residence time, organic loading rate, and algae and food waste content in the feed on volatile solids destruction.

\begin{tabular}{lcccc}
\hline \hline Predictor & Coefficient & Standard Error & $\mathrm{t}$ & $\mathrm{p}$ \\
Constant & & & & \\
Residence Time & 48.941 & 5.883 & 8.32 & 0.000 \\
OLR & 0.1879 & 0.2213 & 0.85 & 0.411 \\
Algae & 0.5869 & 0.9517 & 0.62 & 0.548 \\
Food Waste & -0.27481 & 0.03759 & -7.31 & 0.000 \\
& 0.34923 & 0.04767 & 7.33 & 0.000 \\
\hline R-Squared & & & & \\
\hline
\end{tabular}

The standard residuals for Digester 1.9, 2.3, 2.4, 2.5 and 2.9 were above 1.00 in the volatile solids destruction regression analysis (Figure 23). These larger standard residuals were evenly distributed above and below the line of best fit, from low to high volatile solids destruction, and have no readily apparent relationship to any specific variable. Therefore, the larger standard residuals are most likely attributable to natural variation.

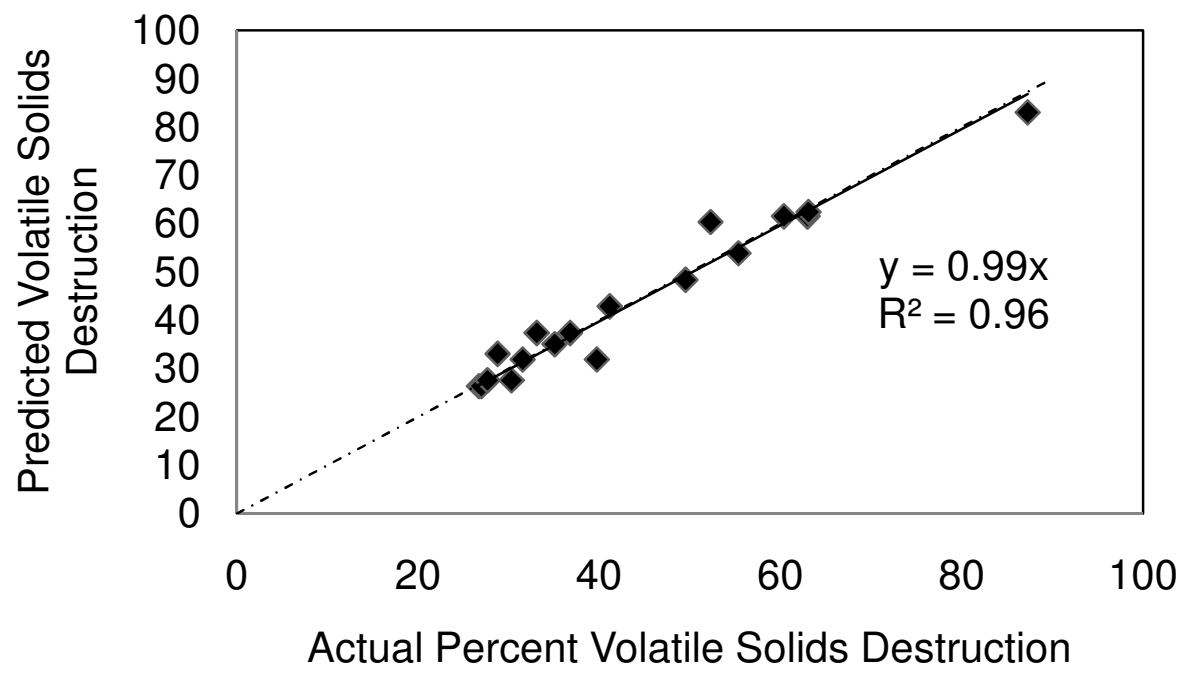

Figure 23: Plot showing the predicted volatile solids destruction as determined from the extended model equation compared to the actual measured average volatile solids 
destruction for the steady state period. The dashed line indicates the one to one line while the solid line indicates the line of best fit for the data points.

\section{COMPACT MODELS}

Equations for the compact model were determined based on the p-values in the extended models. P-values less than 0.05 were defined as to be statistically significant in this work, and new models and equations were developed using only the variables that yielded p-values less than 0.05 . Residence time was eliminated as a variable in the compact model due to only two residence times being tested with no duplicates for the longer residence time. In some cases, such as the biogas composition equation, eliminating residence time resulted in p-values for some variables that were now greater than 0.05. These variables were also eliminated from the compact model, and the equation was recalculated until all p-values were less than 0.05 . Unusual values indicate values with large standardized residuals. The final compact models are shown in Equations 9-14.

$$
\begin{array}{rr}
\text { Alkalinity }\left(\mathrm{mg} \mathrm{CaCO}_{3} / \mathrm{L}\right)=2284+1414 \mathrm{OLR}(\mathrm{g} \mathrm{VS} / \mathrm{L}-\mathrm{d})+21.1 \mathrm{Algae}(\%) ; \\
\mathrm{R}^{2}=85.6 \% & \text { Equation } 9
\end{array}
$$

Table 11: Compact model statistics showing the influence of organic loading rate and

\begin{tabular}{|c|c|c|c|c|}
\hline Predictor & Coefficient & Standard Error & $\mathrm{t}$ & $\mathrm{p}$ \\
\hline Constant & 2284 & 585.5 & 3.90 & 0.001 \\
\hline OLR & 1414.2 & 166.2 & 8.51 & 0.000 \\
\hline Algae & 2.116 & 6.01 & 3.51 & 0.003 \\
\hline \multicolumn{5}{|c|}{ Unusual Observations: Digester 2.10} \\
\hline R-Squared & $85.6 \%$ & & & \\
\hline
\end{tabular}
algae content in the feed on digester alkalinity concentration. 
Volatile Fatty Acids $(m g$ as acetic acid/L) $=-2912.9+1649.7$ OLR $(\mathrm{g} \mathrm{VS} / \mathrm{L}-\mathrm{d})+$

34.12 Food $(\%) ; \mathrm{R}^{2}=75.9 \%$

Equation 10

Table 11: Compact model statistics showing the influence of organic loading rate and food waste content in the feed on digester volatile fatty acid concentration.

\begin{tabular}{lcccc}
\hline \hline Predictor & Coefficient & Standard Error & $\mathrm{t}$ & $\mathrm{p}$ \\
\hline \multicolumn{5}{c}{} \\
Constant & -2912.9 & 870.5 & -3.35 & 0.004 \\
OLR & 1649.7 & 312.5 & 5.28 & 0.000 \\
Food Waste & 34.12 & 13.86 & 2.46 & 0.026 \\
Unusual Observations: Digester 2.8 and 2.9 & & \\
\hline
\end{tabular}

Ammonia (mg N/L) $=370+506$ OLR (g VS/L-d) + 7.17 Algae (\%); $\mathrm{R}^{2}=84.9 \%$

Equation 11

Table 13: Compact model statistics showing the influence of organic loading rate and algae content in the feed on digester ammonia nitrogen concentration.

\begin{tabular}{lcccc}
\hline \hline Predictor & Coefficient & Standard Error & $\mathrm{t}$ & $\mathrm{p}$ \\
\hline \multicolumn{5}{c}{} \\
Constant & 370.0 & 213.3 & 1.73 & 0.103 \\
OLR & 505.89 & 60.55 & 8.36 & 0.000 \\
Algae & 7.167 & 2.190 & 3.27 & 0.005 \\
Unusual Observations: Digester 2.10 & & & \\
\multicolumn{2}{l}{ R-Squared } & & & \\
\hline
\end{tabular}

Biogas Quality (percent $\left.\mathrm{CH}_{4}\right)=70.3-0.194$ Food Waste $(\%) ; \mathrm{R}^{2}=70.4 \%$

Equation 12 
Table 14: Compact model statistics showing the influence of food waste content in the feed on biogas quality.

\begin{tabular}{lcccc}
\hline \hline Predictor & Coefficient & Standard Error & $\mathrm{t}$ & $\mathrm{p}$ \\
\hline & & & & \\
Constant & 70.2607 & 0.9633 & 72.93 & 0.000 \\
Food Waste & -0.19307 & 0.03139 & -6.17 & 0.000 \\
Unusual Observations: 2.9 & & & \\
\hline \multicolumn{2}{l}{ R-Squared } & $70.4 \%$ & &
\end{tabular}

Yield $(\mathrm{mL} \mathrm{CH} 4 / \mathrm{g}$ VS $)=515-38.4$ OLR $(\mathrm{g}$ VS/L-d $)-1.76$ Algae $(\%)+1.59$ Food

$$
\text { Waste }(\%) ; \mathrm{R}^{2}=80.2 \%
$$

Equation 13

Table 15: Compact model statistics showing the influence of organic loading rate, and algae and food waste content in the feed on methane yield.

\begin{tabular}{lcccc}
\hline Predictor & Coefficient & Standard Error & $\mathrm{t}$ & $\mathrm{p}$ \\
\hline \multicolumn{5}{l}{} \\
Constant & 515.49 & 40.24 & 12.81 & 0.000 \\
OLR & -38.37 & 11.87 & -3.23 & 0.006 \\
Algae & -1.7625 & 0.4938 & -3.57 & 0.003 \\
Food Waste & 1.5878 & 0.6381 & 2.49 & 0.026 \\
Unusual Observations: Digester 2.9 & & & \\
\hline R-Squared & $80.2 \%$ & & \\
\hline
\end{tabular}

Percent Volatile Solids Destruction $=53.7-0.264$ Algae $(\%)+0.360$ Food $(\%)$;

$$
\mathrm{R}^{2}=95.6 \% \quad \text { Equation } 14
$$

Table 12: Compact model statistics showing the influence of algae and food waste

\begin{tabular}{|c|c|c|c|c|}
\hline Predictor & Coefficient & Standard Error & $\mathrm{t}$ & $\mathrm{p}$ \\
\hline Constant & 53.682 & 2.551 & 21.04 & 0.000 \\
\hline Algae & -0.26407 & 0.03339 & -7.91 & 0.000 \\
\hline Food Waste & 0.36033 & 0.04093 & 8.80 & 0.000 \\
\hline \multicolumn{5}{|c|}{ Unusual Observations: Digester 2.5} \\
\hline R-Squared & $95.6 \%$ & & & \\
\hline
\end{tabular}
content in the feed on volatile solids destruction. 


\section{CONCLUSIONS}

The major goal of this research was to produce high methane yields from algae digestion or co-digestion while maintaining digester stability and avoiding the need for alkalinity addition. Stable digestion was achieved at organic loading rates from 1 to $4 \mathrm{~g} \mathrm{VS/L-d}$ and 20 and 40 day residence times for all feed combination. Stable digestion with a methane yield of 0.23 to $0.25 \mathrm{~L} \mathrm{CH}_{4} / \mathrm{g} \mathrm{VS}_{\text {in }}$ was measured for digesters exclusively fed algae biomass at loading rates of 2 to $4 \mathrm{~g} \mathrm{VS} / \mathrm{L}$-day and a 20-day residence time. The highest yield of $0.40 \mathrm{~L} \mathrm{CH}_{4} / \mathrm{g} \mathrm{VS}_{\text {in }}$ for algae co-digestion was observed with a feed makeup of 50\% food waste, $40 \%$ algae, and $10 \%$ wastewater sludge at a 20 -day residence time and a loading rate of $2 \mathrm{~g}$ VS/L-day. Additionally, these results were compiled into multivariable extended and compact models in order to characterize the effect of organic loading rate, residence time, and feed composition on methane yield, biogas quality, volatile solids destruction, alkalinity, volatile fatty acids, and ammonia nitrogen concentrations.

A synergistic effect for algae and sludge co-digestion was not observed. Increasing sludge content in the feed linearly increased the methane yield. The yield for digesters fed $100 \%$ algae loaded at $2 \mathrm{~g} \mathrm{VS} / \mathrm{L}-\mathrm{d}$ and a 20 -day residence time was $0.25 \mathrm{~L} \mathrm{CH}_{4} / \mathrm{g}$ $\mathrm{VS}_{\mathrm{in}}$, and the yield for digesters fed $100 \%$ sludge with the same loading rate and residence time was $0.42 \mathrm{~L} \mathrm{CH}_{4} / \mathrm{g} \mathrm{VS}_{\text {in }}$. The yield for digesters fed $40 \%$ algae and $60 \%$ sludge loaded at $2 \mathrm{~g} \mathrm{VS} / \mathrm{L}-\mathrm{d}$ and a 20 -day residence time was $0.38 \mathrm{~L} \mathrm{CH}_{4} / \mathrm{g} \mathrm{VS}_{\mathrm{in}}$, and the yield for digesters fed $40 \%$ algae, $50 \%$ food waste and $10 \%$ sludge with the same loading 
rate and residence time was slightly higher at $0.40 \mathrm{~L} \mathrm{CH}_{4} / \mathrm{g} \mathrm{VS}_{\text {in. }}$ Adding food waste likely improved methane yields by simply providing a more energy-rich substrate.

Total ammonia nitrogen concentrations did not appear to inhibit methane yield. Digesters with the same feed content and residence time loaded at 2 and $4 \mathrm{~g} \mathrm{VS} / \mathrm{L}-\mathrm{d}$ had similar yields, despite greatly different total ammonia nitrogen concentrations of 1740 and $3370 \mathrm{mg} / \mathrm{L}$, respectively. The methanogens used in this study were taken from a municipal wastewater sludge digester where relatively high ammonia nitrogen concentrations of $1700 \mathrm{mg} \mathrm{N} / \mathrm{L}$ were present. This presents the possibility that ammoniaadapted cultures can be used to avoid ammonia toxicity and inhibition problems despite the high nitrogen content of the algal substrate. Additionally, serial inoculation from previous algae digesters at the start of each experiment may have contributed to ammonia adaptation. Ammonia-adapted methanogens may have obscured any potential synergistic effect.

In the present study, the factor limiting methane yields appeared to be the resistance of algae cell walls to digestion. As evidenced by the low volatile solids destruction (28\%) in digesters fed $100 \%$ algae compared to the digesters fed only sludge (55\%) or only sludge and food waste (87\%). The presence of intact algae cell walls observed by microscope after 20 and 40 days of digestion also points to the resistance of algae cell walls to digestion.

In addition to the possible benefit of algae digestion to wastewater treatment pond facilities, systems to produce liquid biofuel from algae might be able to recover nutrients 
and carbon from residual algae biomass after oil extraction. Future research should focus on the digestion of residual algae cell mass after lipid extraction. However, because the removed lipids are high in carbon, ammonia inhibition could be expected to be even more prevalent. In this case, co-digestion of residual algae cell mass with a high carbon substrate such as food waste could improve process stability and yields. Additionally, more research is needed to compare the effects of using ammonia adapted cultures to the effects of co-digestion. Finally, more research is needed to determine what constituents of wastewater grown algae biomass actually digest, and develop cost effective methods for penetrating algae cell walls. 


\section{REFERENCES}

APHA (2005). Standard Methods for the Examination of Water \& Wastewater. American Public Health Association, Water Environment Federation, and the American Waterworks Association.

California Energy Commission. Bioenergy Action Plan for California, 2006. Web. 26 May 2011. < http://www.energy.ca.gov/2006publications/CEC-600-2006-010/CEC600-2006-010.PDF>.

California Energy Commission. California Renewable Energy Overview and Programs, 2011. Web. 26 May 2011. <http://www.energy.ca.gov/renewables/index.htmL>.

California Energy Commission. Renewable Energy Programs. 2011. Web. 26 May 2011. $<$ http://www.energy.ca.gov/renewables/renewable_links.htmL>.

Chen, P. H., \& Oswald, W. J. (1998). Thermochemical treatment for algal fermentation. Environment International, 24(8), 889-897. doi:10.1016/S0160-4120(98)00080-4

De Sa, J. (2009). Personnel communication. Operations Manager, Sunnyvale Water Pollution Control Plant, Sunnyvale, Calif.

EAO, Inc., \& Bracewell Engineering, Inc. (1988). Alage Digestion Study: City of Sunnyvale, Sunnyvale, Calif.

Germain, R., \& Katofsky, R. Bioenergy Interagency Working Group. Recommendations for a Bioenergy Plan for California. 2006. Web. 30 May 2011. 
$<$ http://www.energy.ca.gov/2006publications/CEC-600-2006-004/CEC-600-2006004-F.PDF>.

Golueke, C. G., Oswald, W. J., \& Gotaas, H. B. (1957). Anaerobic Digestion of Algae. Applied and Environmental Microbiology, 5(1), 47.

Hashimoto, A. G. (1986). Ammonia Inhibition of Methanogenesis from Cattle Wastes. Agricultural Wastes, 17(4), 241-261.

Heimel, D.E. (2010). Anaerobic Co-digestion of Wastewater Treatment Pond Algae with Wastewater Sludge, Master's Thesis, Civil and Environmental Engineering, California Polytechnic State University, San Luis Obispo, p.56.

Koster, I. W., \& Lettinga, G. Anaerobic Digestion at Extreme Ammonia Concentrations. Biological Wastes, 25(1), 51-59.

Lundquist (2007). CEC Energy Innovation Small Grants (EISG) proposal.

Lundquist, T. J., Woertz, I. C., Quinn ,N. W. T., \& Benemann, J. R. (2010). "A Realistic Technology and Engineering Assessment of Algae Biofuel Production" Energy Biosciences Institute. <http://works.bepress.com/tlundqui/5>

McCarty, P. L. (1964). Anaerobic Waste Treatment Fundamentals. Public Works, 123126. 
Samson, R. \& LeDuy, A. (1983). Improved performance of anaerobic digestion of Spirulina maxima algal biomass by addition of carbon-rich wastes. Biotechnology Letters, 5(10) 677-682.

Sialve, B., Bernet, N., \& Bernard, O. (2009). Anaerobic digestion of microalgae as a necessary step to make microalgal biodiesel sustainable. Biotechnology Advances, 27(4), 409-416.

Tchobanoglous, G., Burton, F. L., \& Stensel, H. D. (2003). Wastewater Engineering: Treatment and Reuse. New York: McGraw-Hill Science/Engineering/Math.

U.S. DOE 2010. National Algal Biofuels Technology Roadmap. U.S. Department of Energy, Office of Energy Efficiency and Renewable Energy, Biomass Program. $<$ http://biomass.energy.gov>

Yen, H. W., \& Brune, D. E. (2007). Anaerobic co-digestion of algal sludge and waste paper to produce methane. Bioresource Technology, 98(1), 130-134.

Zhang, R., El-Mashad, H. M., Hartman, K., Wang, F., Liu, G., Choate, C., \& Gamble, P. (2007). Characterization of food waste as a feedstock for anaerobic digestion. Bioresource Technology, 98(9), 929-935. 